\title{
Avaliação cefalométrica do tratamento da Classe II, divisão 1, de Angle com os aparelhos extrabucal de Kloehn e fixo edgewise: Influência do padrão facial
}

Lídia Parsekian MARTINS*, Ary dos Santos PINTO**, Luiz Gonzaga GANDINI JÚNIOR***,

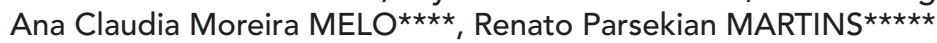

\section{Resumo}

O presente estudo foi realizado com o propósito de avaliar respostas cefalométricas ao tratamento com aparelho extrabucal de Kloehn associado ao aparelho fixo edgewise convencional. Telerradiografias iniciais (T1) e finais (T2) de dois grupos de 30 pacientes tratados com estes aparelhos foram selecionadas e definidas pelo índice cefalométrico de Jarabak para determinação do padrão esquelético craniofacial. Os grupos foram denominados favorável (hipodivergente) e desfavorável (hiperdivergente). A idade média, no início do tratamento, foi de 11,03 anos e final de 14,72 com o tempo médio de tratamento de 3,6 anos para o grupo favorável. No grupo desfavorável a idade inicial foi de 11,51 anos e final de 15,17 anos com tempo médio de tratamento de 3,4 anos. Foi utilizado um sistema de análise de resposta de tratamento em coordenadas $\mathrm{X}$ e $\mathrm{Y}$ representativos dos movimentos dentários e das bases ósseas decompondo-os em seus vetores horizontais e verticais. Os resultados e respostas do tratamento foram analisados e comparados entre os grupos favorável e desfavorável utilizando o teste t-Student. Os resultados mostraram não haver diferenças estatisticamente significantes na resposta cefalométrica no tratamento com o aparelho extrabucal de Kloehn associados ao aparelho fixo edgewise quanto aos padrões faciais favorável e desfavorável. O tratamento promoveu uma restrição do deslocamento anterior maxilar e um menor deslocamento anterior mandibular. Quanto à movimentação dentária maxilar, houve uma restrição do movimento mesial e extrusivo dos molares superiores no grupo favorável, enquanto que o movimento dos dentes inferiores foi mínimo no sentido anterior e vertical.

Palavras-chave: Cefalometria. Classe II. Extrabucal. Kloehn.

\footnotetext{
* Professora Assistente-Doutora do Departamento de Clínica Infantil da FOAr/UNESP; Mestrado e Doutorado em Ortodontia da FOAr/UNESP.

** Professor Adjunto do Departamento de Clínica Infantil da FOAr/UNESP; Vice-Coordenador do Programa de Pós-Graduação; Mestrado e Doutorado em Ortodontia da FOAr/UNESP.

*** Professor Assistente-Doutor do Departamento de Clínica Infantil da FOAr/UNESP; Mestrado e Doutorado em Ortodontia da FOAr/UNESP.

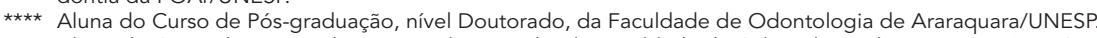

$\star \star \star \star \star$ Aluno do Curso de Pós-graduação, nível Mestrado, da Faculdade de Odontologia de Araraquara/UNESP.
} 


\section{INTRODUÇÃO}

A má oclusão de Classe II, divisão 1, de Angle é uma desarmonia dentofacial de natureza complexa que se caracteriza, genericamente, por uma relação ântero-posterior da arcada dentária superior à frente da arcada dentária inferior. Essa má oclusão poderá apresentar os dentes com mau posicionamento, as bases ósseas maxilares em má relação ou, ainda, os dois componentes envolvidos. A etiologia desta deformidade se define num espectro multifatorial ainda desconhecido totalmente, envolvendo a constituição genética do indivíduo que está crescendo sob diferentes influências ambientais. Os desvios de forma, posição e tamanho dos dentes do próprio osso mandibular têm sido considerados, mais recentemente, como responsáveis pela maioria das más oclusões Classe II $^{13,14,25}$.

A população exibe, na verdade, diferentes subtipos de más oclusões de Classe II que suscitam, por sua vez, diferentes estratégias de tratamentos. Tradicionalmente, os ortodontistas têm agrupado as más oclusões baseando-se na dimensão ântero-posterior e têm ainda considerado que a má oclusão de Classe II pode ser convenientemente tratada pelo controle da posição dos dentes e/ou do crescimento da base óssea do maxilar superior. O aparelho de eleição para este tratamento tem sido o aparelho extrabucal de Kloehn.

Tem sido considerado, mais recentemente, que o controle vertical e do osso basal da maxila durante o tratamento é fundamental para a correção ântero-posterior. $\mathrm{O}$ controle das extrusões dentárias evitaria um giro desfavorável da base mandibular, que traria como conseqüência um aumento da discrepância ântero-posterior. Quando as extrusões dentárias ocorrem no segmento posterior, o mento se desloca para posterior, o que dificulta a correção da Classe II, resultando também numa estética desfavorável.

Está bem aceito na literatura que a má oclusão de Classe II mostra aumento na dimensão vertical, manifestado pela altura facial inferior, aumento do ângulo do plano mandibular, abertura do eixo Y, rotação anti-horária do plano palatino e maior

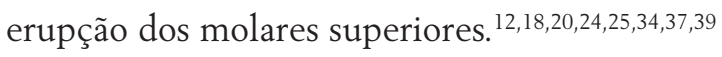

As opiniões de pesquisadores têm destacado, de uma forma inequívoca, que os tratamentos direcionados à face inferior deveriam ter mais ênfase na Ortodontia contemporânea. Esta direção do pensamento está baseada no fato de que qualquer estímulo de rotação anti-horária mandibular é favorável ao tratamento.

Aparelhos ortopédicos que estimulam o crescimento mandibular estão substituindo os aparelhos extrabucais, principalmente nos casos considerados de padrão neutro ou mesmo naqueles que tendem para o padrão horizontal. Uma das fortes razões para a restrição do uso dos aparelhos extrabucais em detrimento dos aparelhos funcionais é a possibilidade de extrusão dos molares provocada pela tração cervical cuja linha de força, teoricamente, sempre exibirá um componente vertical de extrusão. Entretanto a literatura mostra várias investigações que não sustentam a ocorrência da extrusão dos molares durante o tratamento ${ }^{13,14,15,25}$. Por outro lado, ainda existem investigadores e clínicos que acreditam que o resultado do tratamento com o aparelho extrabucal não é diferente do resultado do tratamento com aparelhos ortopédicos. Existe ainda uma controvérsia com relação ao resultado do tratamento com o aparelho extrabucal, se a resposta seria esquelética ou simplesmente dento-alveolar. Como os métodos de superposição cefalométrica foram muito pouco utilizados no passado, acredita-se que controvérsias existiam mais por um problema de metodologia de pesquisas. Além disto, os dados sobre os quais se estabeleceram estas idéias e tendências vieram de estudos limitados por amostras pequenas, método cefalométrico onde o nível de erro não foi controlado e, na grande maioria deles, evidencia-se ausência de superposições cefalométricas e quando efetuado, o método foi inadequado. Técnicas mais aprimoradas de superposições de traçados e o recente aperfeiçoamento de análises cefalométricas 
computadorizadas estimulam análises comparativas para elucidar velhas controvérsias. Assim, parece conveniente rever o efeito de um mesmo tipo de tratamento convencional sobre diferentes padrões faciais.

\section{PROPOSIÇÃO}

O objetivo genérico da presente investigação é proporcionar dados para o conhecimento das respostas de tratamento ortodôntico da Classe II, divisão 1, de Angle.

Os objetivos específicos são os de testar as seguintes hipóteses:

1) As respostas do tratamento ortodôntico com o aparelho extrabucal de Kloehn associado ao aparelho fixo não são diferentes quando considerados os padrões faciais pré-estabelecidos: favorável e desfavorável.

2) As respostas do tratamento ortodôntico com o aparelho extrabucal de Kloehn associado ao aparelho fixo não são diferentes quando consideradas as respostas da maxila e da mandíbula.

3) As respostas do tratamento ortodôntico com o aparelho extrabucal de Kloehn associado ao aparelho fixo não são diferentes quando consideradas alterações dento-alveolares e de base óssea.

\section{MATERIAL E MÉTODO}

Foram constituídos dois grupos de 30 pacientes brasileiros, leucodermas, portadores de má oclusão de Classe II, divisão 1, de Angle. A seleção desse grupo de pacientes foi realizada tendo como base a documentação existente nos arquivos do curso de Pós-graduação em Ortodontia da Faculdade de Odontologia de Araraquara - UNESP e de alguns consultórios particulares da região, que possuíam radiografias tomadas no serviço de Radiologia daquela Faculdade.

O critério de inclusão na amostra foi a seleção de radiografias em norma lateral de pacientes com as seguintes características:

1) Pacientes com má oclusão Classe II, divisão 1, de Angle, definido pelo trespasse moderado a acentuado, relação de caninos e molares topo a topo à Classe II completa no início do tratamento.

2) Idade de 8 a 14 anos.

3) Pacientes que fizeram uso do aparelho extrabucal com tração do tipo cervical durante o tratamento.

4) Tratamento realizado com aparelho fixo utilizando a técnica de Edgewise convencional.

5) Tratamento executado sem extrações dentárias.

6) Pacientes que não tiveram qualquer outro tipo de tratamento ortodôntico.

Estes dois grupos foram definidos pelo índice cefalométrico de Jarabak (obtido pela relação entre a Altura Facial Posterior, multiplicado por 100, e dividido pela Altura Facial Anterior e expresso em porcentagem) que determina o padrão esquelético crâniofacial, denominado Desfavorável (D) ou Favorável (F) (Fig. 1).

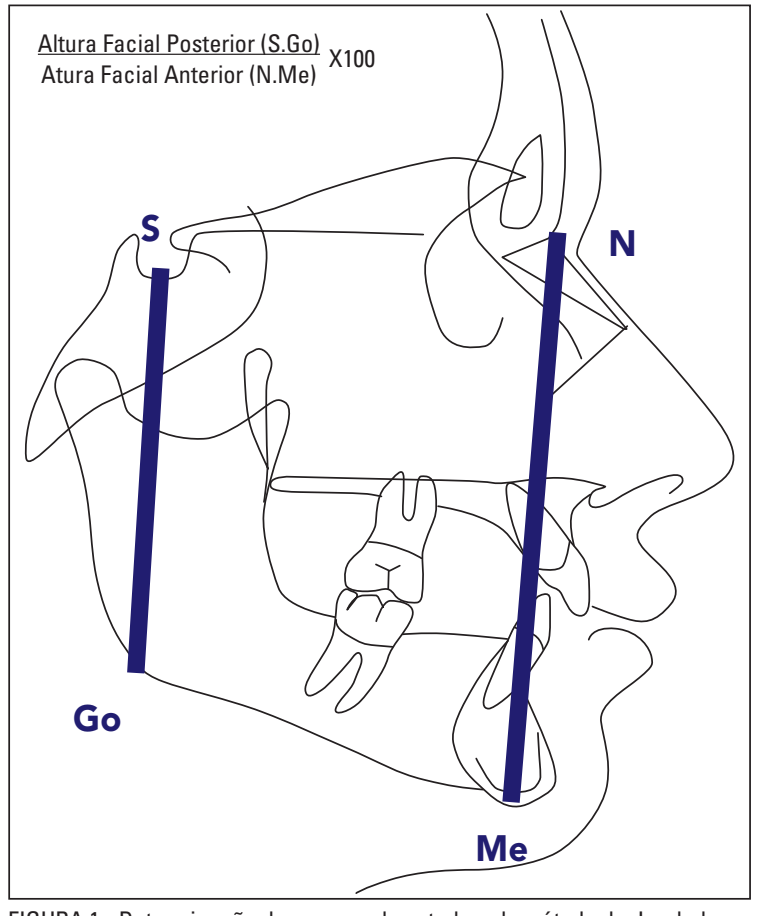

FIGURA 1 - Determinação dos grupos de estudo pelo método de Jarabak. 


Tabela 1 - Caracterização do padrão facial
da amostra segundo o índice cefalométrico de Jarabak.
\begin{tabular}{|c|c|c|c|c|c|}
\hline Tipo Facial & $\mathrm{n}$ & Média & D.P. & Min. & Max. \\
\hline Desfavorável & 30 & 54,23 & 2,67 & 45,10 & 58,00 \\
\hline Favorável & 30 & 62,13 & 3,23 & 58,20 & 70,50 \\
\hline
\end{tabular}

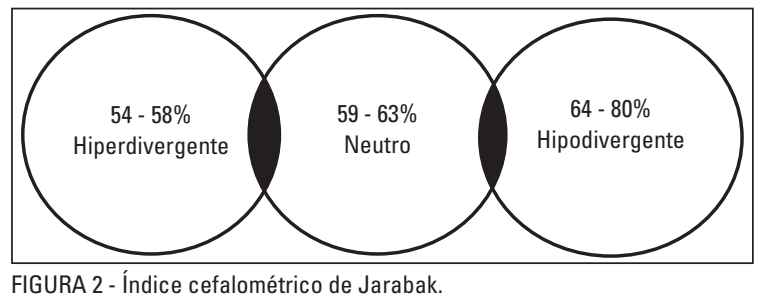

FIGURA 2 - Índice cefalométrico de Jarabak.

\begin{tabular}{|c|c|c|c|c|c|c|c|c|c|c|}
\hline \multirow{2}{*}{ Gênero } & \multirow{2}{*}{ Tipo Facial } & \multirow{2}{*}{$\mathrm{n}$} & \multicolumn{4}{|c|}{ Idade Inicial } & \multicolumn{4}{|c|}{ Idade Final } \\
\hline & & & Média & D.P. & Min. & Máx. & Média & D.P. & Min & Máx \\
\hline \multirow[t]{2}{*}{ Feminino } & Desfavorável & 20 & 10,93 & 1,13 & 8,90 & 13,13 & 14,19 & 1,12 & 11,62 & 16,01 \\
\hline & Favorável & 26 & 10,85 & 1,12 & 9,16 & 13,56 & 14,43 & 1,31 & 11,79 & 16,82 \\
\hline \multirow[t]{2}{*}{ Masculino } & Desfavorável & 10 & 11,51 & 1,27 & 9,51 & 13,03 & 15,17 & 1,13 & 13,32 & 16,92 \\
\hline & Favorável & 4 & 11,03 & 0,62 & 10,43 & 11,88 & 14,72 & 1,40 & 13,64 & 16,74 \\
\hline
\end{tabular}

O grupo I, chamado Desfavorável, foi composto por 30 pacientes cujos índices de Jarabak apresentavam valores menores ou iguais a $58 \%$, representativos de padrão hiperdivergente, enquanto que o grupo II, denominado Favorável, foi composto por outros 30 pacientes que apresentavam valores maiores que $58 \%$, com padrão hipodivergente e que incluíam alguns pacientes com crescimento equilibrado. (Tab. 1, Fig. 2).

Para todos os pacientes foram utilizadas duas telerradiografias, uma tomada ao início e outra ao final do tratamento com aparelho extrabucal do tipo Kloehn tração cervical e aparelho fixo edgewise convencional, consideradas respectivamente como T1 (inicial) e T2 (final). As telerradiografias foram traçadas e digitadas para análise cefalométrica.

Pacientes de ambos os gêneros compuseram a amostra cujas idades médias constam na tabela 2 .

Todas as radiografias foram tomadas em aparelhos ASAHI-Panoramax, tendo como critério de padronização a distância foco-filme de 1,52 m e a utilização de cefalostato do tipo Broadbent.

O tratamento da má oclusão de Classe II, divisão 1, de Angle foi realizado segundo protocolo convencional. O aparelho utilizado para a correção da relação ântero-posterior de molares foi o extrabucal do tipo Kloehn com tração cervical. Este foi mantido até que os primeiros molares alcançassem uma relação de molar de Classe I. A maioria dos pacientes recebeu aparelhos fixos do tipo edgewise convencional .022" $\mathrm{x} .028$ " no arco superior antes que a relação de molares estivesse totalmente corrigida. Nos demais pacientes, o referido aparelho fixo foi instalado logo após a obtenção da relação de molar de Classe I.

A seqüência clínica para a instalação do aparelho extrabucal foi primeiramente, a bandagem dos primeiros molares superiores, seguida do ajuste do arco interno do extrabucal de forma que a porção anterior do seu arco externo estivesse de 0,5 a $1 \mathrm{~cm}$ à frente dos lábios e que, ao fechar a boca, o paciente apresentasse igual pressão no lábio superior e inferior. Em seguida as extremidades do arco externo eram ajustadas de 0,5 a $1 \mathrm{~cm}$ distal ao nível dos primeiros molares superiores. Uma almofada cervical foi ajustada ao pescoço do paciente de forma que elásticos bilaterais, com forças que variaram de 250 a 400 gramas, pudessem ser enganchados para proporcionar esta pressão sobre os primeiros 


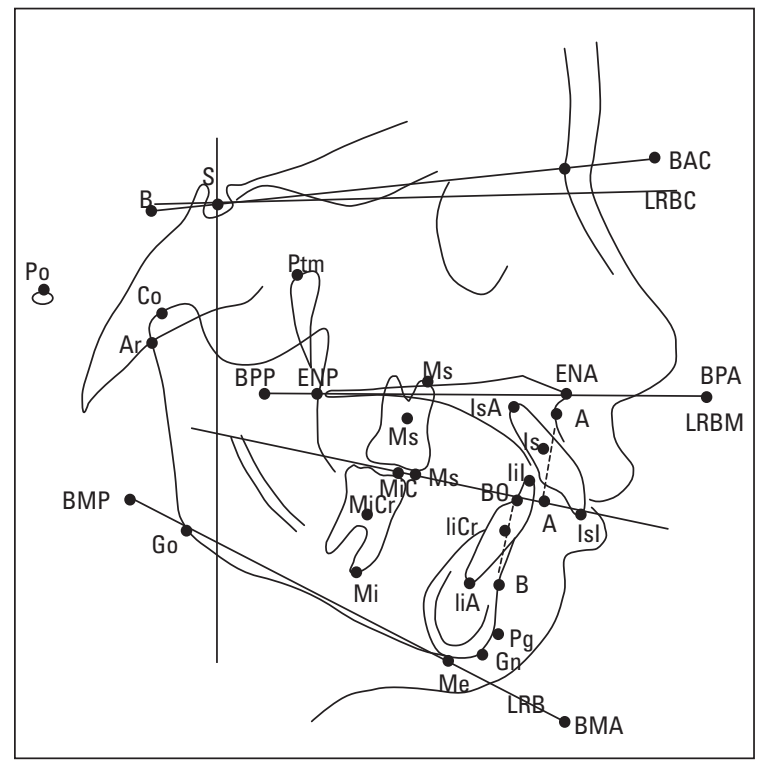

FIGURA 3 - Pontos cefalométricos e linhas de referência.

molares superiores de cada lado. Os pacientes foram instruídos a utilizar este aparelho diária e intermitentemente num intervalo de tempo que variou de 12 a 18 horas por dia.

Quando a relação dos molares, caninos e/ ou a sobressaliência estavam corrigidas e, ainda, em outros casos quando o tratamento foi concluído, tomou-se uma nova telerradiografia para avaliação do resultado do tratamento. Estas radiografias foram consideradas todas como pós-tratamento (final T2). As idades iniciais dos pacientes representavam as idades das tomadas das telerradiografias e, desta forma, deve-se considerar que os tratamentos, provavelmente, tenham sido iniciados algum tempo após (uma semana a 1 mês) as tomadas das telerradiografias (iniciais T1).

Para se computar corretamente as idades dos pacientes e anualizar as alterações morfológicas provocadas pelo crescimento e/ou pelo tratamento nas variáveis estudadas, foi adotado o método preconizado por De Marshall ${ }^{10}$, que identifica em decimais o dia exato da ocorrência de cada evento: nascimento, primeira e segunda tomadas das telerradiografias. Assim, todas as alterações foram

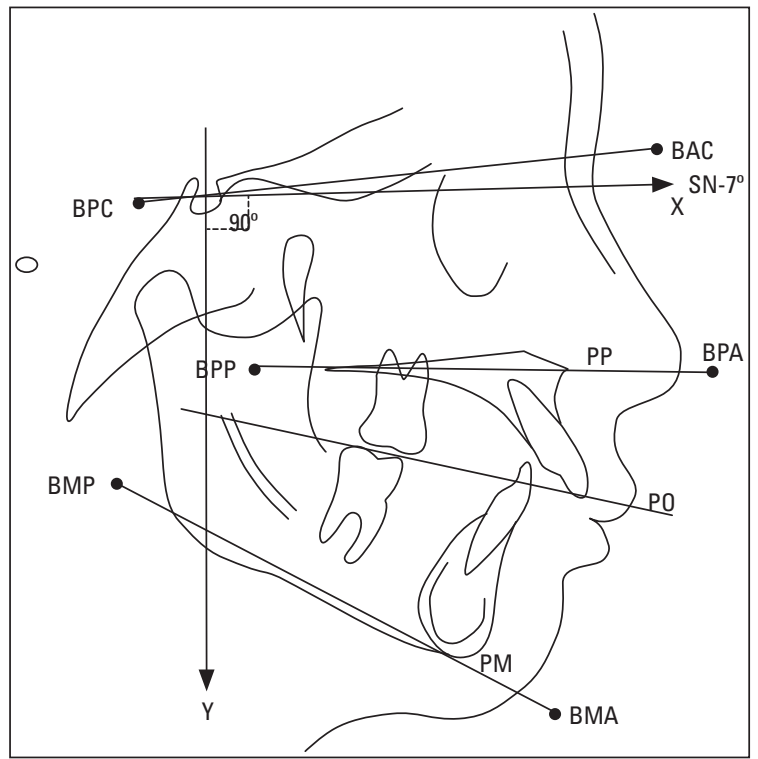

FIGURA 4 - Pontos fiduciais, planos e linhas cefalométricas.

computadas, descrevendo-as com base nas mudanças anuais das grandezas cefalométricas, em milímetros ou graus por ano, conforme a seguinte fórmula:

$$
\frac{\text { VARIÁVEL }_{\text {tempo2 }}-\text { VARIÁVEL }_{\text {tempol }}}{\text { IDADE }_{\text {tempo2 }}-\text { IDADE }_{\text {tempol }}}
$$

Um cefalograma em norma lateral foi traçado pelo mesmo operador sobre cada telerradiografia previamente obtida. As estruturas bilaterais foram ambas traçadas e considerou-se uma média no momento da determinação dos pontos cefalométricos. Os pontos cefalométricos demarcados e digitados nesse estudo (Fig. 3) seguiram as definições descritas por Riolo et al. ${ }^{36}$ (Tab. 3). Pontos fiduciais e planos adicionais foram determinados a partir desses pontos cefaloméricos para representar a base do crânio, o plano palatino, o plano oclusal e o plano mandibular (Fig. 4). O plano da base do crânio foi obtido pela linha sela-násio, o plano palatino pela espinha nasal anterior e posterior, o plano oclusal pelo ponto intermediário das cúspides dos primeiros molares superiores e inferiores e incisivos centrais, e o plano mandibular através dos pontos gônio e mentoniano (Fig. 4). 


\begin{tabular}{|c|c|c|}
\hline Abreviação & Ponto cefalométrico & Definição \\
\hline S & Sela & Centro geométrico da sela túrcica \\
\hline $\mathrm{N}$ & Násio & Ponto mais anterior na sutura fronto-nasal \\
\hline A & Subespinhal & Ponto mais profundo na concavidade anterior da maxila \\
\hline B & Supramentoniano & Ponto mais posterior na concavidade anterior da mandíbula \\
\hline $\mathrm{Pg}$ & Pogônio & Ponto mais anterior no contorno anterior da sínfise mandibular \\
\hline Po & Pório & Ponto mais superior e posterior da imagem do conduto auditivo \\
\hline Ao & A (Oclusal) & Projeção ortogonal do ponto A sobre o plano oclusal \\
\hline Bo & B (Oclusal) & Projeção ortogonal do ponto A sobre o plano oclusal \\
\hline $\mathrm{Ar}$ & Articular & $\begin{array}{l}\text { Ponto de intersecção da borda posterior do ramo da mandíbula com a porção posterior do clivus } \\
\text { do osso esfenóide }\end{array}$ \\
\hline Ptm & Fissura ptérigo-maxilar & Ponto mais póstero-superior da fissura ptérigo-maxilar \\
\hline Co & Condílio & Ponto mais póstero-superior da côndilo mandibular \\
\hline $\mathrm{Gn}$ & Gnátio & Ponto mais ântero-inferior no contorno anterior da sínfise mandibular \\
\hline Me & Mentoniano & Ponto mais inferior no contorno inferior da sínfise mandibular \\
\hline IsA & Ápice do Incisivo Superior & Ápice do Incisivo Central Superior \\
\hline $\mathrm{IsCr}$ & $\begin{array}{l}\text { Centro de Resistência do incisivo } \\
\text { superior }\end{array}$ & $\begin{array}{c}\text { Centro de Resistência do Incisivo Central Superior localizado no terço cervical da raiz do incisivo } \\
\text { central superior }\end{array}$ \\
\hline$|s|$ & Borda do Incisivo Superior & Borda Incisal do Incisivo Central Superior \\
\hline Mas & $\begin{array}{l}\text { Ápice Mesial do Primeiro Molar } \\
\text { Superior }\end{array}$ & Ápice da Raiz Mesial do Primeiro Molar Superior \\
\hline $\mathrm{MsCr}$ & $\begin{array}{l}\text { Centro de Resistência do Molar } \\
\text { Superior }\end{array}$ & Centro de Resistência do Primeiro Molar Superior localizado na trifurcação radicular \\
\hline $\mathrm{MsC}$ & Cúspide do Molar Superior & Cúspide mésio-vestibular do primeiro molar superior \\
\hline liA & Ápice do Incisivo Inferior & Ápice Radicular do Incisivo Central Inferior \\
\hline $\mathrm{liCr}$ & $\begin{array}{l}\text { Centro de Resistência do incisivo } \\
\text { inferior }\end{array}$ & $\begin{array}{c}\text { Centro de resistência do incisivo central inferior localizado no terço cervical da raiz do incisivo } \\
\text { central inferior }\end{array}$ \\
\hline lil & Borda do Incisivo Inferior & Borda Incisal do Incisivo Central Inferior \\
\hline MiA & Ápice do Molar Inferior & Ápice da Raiz Mésio-Vestibular do Primeiro Molar Inferior \\
\hline $\mathrm{MiCr}$ & $\begin{array}{l}\text { Centro de Resitência do molar } \\
\text { inferior }\end{array}$ & Centro de resistência do primeiro molar inferior localizado na área da bifurcação radicular \\
\hline MiC & Cúspide do Molar Inferior & Ponta da Cúspide Mésio-Vestibular do Primeiro Molar Inferior \\
\hline Go & Gônio & Ponto mais póstero-inferior no contorno externo do ângulo Goníaco \\
\hline ENA & Espinha Nasal Anterior & Ponto mais anterior na margem anterior da abertura piriforme \\
\hline ENP & Espinha Nasal Posterior & Ponto mais posterior na imagem do soalho das fossas nasais \\
\hline & & Pontos Fiduciais \\
\hline Abreviação & Ponto Fiducial & Descrição \\
\hline BPC & Base Posterior do Crânio & $\begin{array}{l}\text { Ponto fiducial localizado na extensão da linha sela-násio da radiografia inicial (T1) posterior ao } \\
\text { ponto sela }\end{array}$ \\
\hline BAC & Base Anterior do Crânio & $\begin{array}{l}\text { Ponto fiducial localizado na extensão da linha sela-násio da radiografia inicial (T1) anterior ponto } \\
\text { násio e ao perfil de tecido mole }\end{array}$ \\
\hline BPP & Base Palatina Posterior & $\begin{array}{l}\text { Ponto fiducial localizado na extensão da linha ENA-ENP da radiografia inicial (T1) posterior à } \\
\text { espinha nasal posterior }\end{array}$ \\
\hline BPA & Base Palatina Anterior & $\begin{array}{l}\text { Ponto fiducial localizado na extensão da linha ENA-ENP da radiografia inicial (T1) anterior à } \\
\text { espinha nasal anterior e ao perfil de tecido mole }\end{array}$ \\
\hline BMP & Base Mandibular Posterior & $\begin{array}{l}\text { Ponto fiducial localizado na extensão da linha Go-Me da radiografia inicial (T1) posterior ao ponto } \\
\text { gônio e borda posterior da mandíbula }\end{array}$ \\
\hline BMA & Base Mandibular Anterior & $\begin{array}{l}\text { Ponto fiducial localizado na extensão da linha Go-Me da radiografia inicial (T1) anterior ao ponto } \\
\text { gnátio perfil de tecido mole }\end{array}$ \\
\hline & & Planos e linhas de referência \\
\hline Abreviação & Planos e Linhas & Descrição \\
\hline SN & Linha Sela-Násio & Linha representada pela união dos pontos $\mathrm{S}$ e $\mathrm{N}$ \\
\hline PM & Plano Mandibular & Linha representada pela união dos pontos Go e Me \\
\hline Plo & Plano Oclusal & $\begin{array}{l}\text { Linha representada pela união dos pontos intermediários das cúspides dos } 1^{\text {os }} \text { molares e dos } \\
\text { incisivos centrais }\end{array}$ \\
\hline PP & Plano Palatino & Linha representada pela união dos pontos ENA e ENP \\
\hline LRBC & $\begin{array}{l}\text { Linha de referência da base do } \\
\text { crânio }\end{array}$ & Linha que passa pelo ponto Sela determinada menos 7 graus em relação à linha BPC e BAC \\
\hline LRBMx & Linha de referência da base maxilar & Linha representada pela união dos pontos fiduciais BPP e BPA \\
\hline LRBMd & $\begin{array}{l}\text { Linha de referência da base } \\
\text { mandibular }\end{array}$ & Linha representada pela união dos pontos BMP e BMA \\
\hline
\end{tabular}




\begin{tabular}{|c|c|}
\hline & $\begin{array}{l}\text { Tabela } 4 \text { - Variáveis cefalométricas tradicionais e distâncias dos pontos } \\
\text { cefalométricos nas coordenadas X e Y - Medidas Esqueléticas e Dentárias. }\end{array}$ \\
\hline VARIÁVEL & DEFINIÇÃO \\
\hline & MEDIDAS ESQUELÉTICAS MAXILARES ÂNTERO-POSTERIORES \\
\hline 1. SNA & Ângulo que mede a posição relativa da maxila no sentido ântero-posterior em relação à base do crânio \\
\hline 2. Co-A & Medida linear ântero-posterior que representa a profundidade da face média \\
\hline 3. A h & Medida linear do ponto $A$, perpendicular à coordenada $X$ \\
\hline 4. ENA h & Medida linear da espinha nasal anterior, perpendicular à coordenada X \\
\hline 5. ENP h & Medida linear da espinha nasal posterior, perpendicular à coordenada $\mathrm{X}$ \\
\hline & MEDIDAS ESQUELÉTICAS MAXILARES VERTICAIS \\
\hline 6. N-ENA & Medida linear que representa a altura facial anterior da face média \\
\hline 7. S-ENP & Medida linear que representa a altura facial posterior da face \\
\hline 8. SN.PP & Ângulo que representa a inclinação do plano palatino em relação à base anterior do crânio \\
\hline 9. $A v$ & Medida linear do ponto $\mathrm{A}$, perpendicular à coordenada $\mathrm{Y}$ \\
\hline 10. ENA v & Medida linear da espinha nasal anterior, perpendicular à coordenada $Y$ \\
\hline 11. ENP v & Medida linear da espinha nasal posterior, perpendicular à coordenada $Y$ \\
\hline & MEDIDAS ESQUELÉTICAS MANDIBULARES ÂNTERO-POSTERIORES \\
\hline 12. B h & Medida linear do ponto $B$, perpendicular à coordenada $X$ \\
\hline 13. Me h & Medida linear do ponto mentoniano, perpendicular à coordenada $X$ \\
\hline 14. Go h & Medida linear do ponto gônio, perpendicular à coordenada X \\
\hline 15. Ar h & Medida linear do ponto articular, perpendicular à coordenada X \\
\hline 16. Gn h & Medida linear do ponto gnátio, perpendicular à coordenada X \\
\hline 17. Co h & Medida linear do ponto condílio, perpendicular à coordenada X \\
\hline 18. Go-Gn & Medida linear que representa o comprimento do corpo mandibular \\
\hline 19. $\mathrm{Ar}-\mathrm{Pg}$ & Distância linear entre o ponto articular e pogônio \\
\hline 20. $\mathrm{Co}-\mathrm{Pg}$ & Medida linear que representa o comprimento total da mandíbula \\
\hline 21. SNB & Ângulo que representa a posição relativa da mandíbula, no sentido ântero-posterior, em relação à base do crânio \\
\hline & MEDIDAS ESQUELÉTICAS MANDIBULARES VERTICAIS \\
\hline 22. $\mathrm{Co}-\mathrm{Go}$ & Medida linear que representa a altura do ramo mandibular \\
\hline 23. S-Go & Medida linear da altura facial total posterior \\
\hline 24. Â.Ramo & Ângulo formado entre o ponto sela, o ponto articular e o ponto gônio \\
\hline 25. Â.Go & Medida angular representativa do ângulo goníaco (Ar.Go.Me) \\
\hline 26. SN.PM & Ângulo que representa a inclinação do plano mandibular em relação à base anterior do crânio \\
\hline 27. Ar v & Medida linear do ponto articular, perpendicular à coordenada $Y$ \\
\hline 28. Co v & Medida linear do ponto condílio, perpendicular à coordenada $Y$ \\
\hline 29. Gn v & Medida linear do ponto gnátio, perpendicular à coordenada Y \\
\hline 30. Go v & Medida linear do ponto gônio, perpendicular à coordenada $Y$ \\
\hline 31. Me v & Medida linear do ponto mentoniano, perpendicular à coordenada $Y$ \\
\hline 32. B v & Medida linear do ponto $B$, perpendicular à coordenada $Y$ \\
\hline & RELAÇÃO INTERMAXILAR ÂNTERO-POSTERIOR \\
\hline 33. $\mathrm{AO}-\mathrm{BO}$ & Iida linear da relação maxilo-mandibular, no sentido ântero-posterior, projetada perpendicularmente no plano oclusal \\
\hline
\end{tabular}




\section{MEDIDAS MAXILARES DENTO-ALVEOLARES ÂNTERO-POSTERIORES}

\begin{tabular}{|c|c|}
\hline 34. $\mathrm{MsC} \mathrm{h}$ & Medida linear da cúspide mésio-vestibular do primeiro molar superior, perpendicular à coordenada $\mathrm{X}$ \\
\hline 35. $\mathrm{MsCrh}$ & Medida linear do centro de resistência do primeiro molar superior, perpendicular à coordenada X \\
\hline 36. MsA h & Medida linear do ápice da raiz mesial do primeiro molar superior, perpendicular à coordenada X \\
\hline 37 Ms.PP & Ângulo que mede a inclinação do longo eixo (ápice-cúspide) do primeiro molar superior, em relação ao plano palatino \\
\hline 38. Ms.SN & Ângulo que mede a inclinação do longo eixo (ápice-cúspide) do primeiro molar superior, em relação à base do crânio \\
\hline 39. IsI h & Medida linear da borda incisal do incisivo central superior, perpendicular à coordenada $\mathrm{X}$ \\
\hline 40. IsCr h & Medida linear do centro de resistência do incisivo central superior, perpendicular à coordenada X \\
\hline 41. IsA h & Medida linear do ápice do incisivo central superior, perpendicular à coordenada X \\
\hline 42. Is.PP & Inclinação do longo eixo (ápice-incisal) do incisivo superior em relação ao plano palatino \\
\hline 43. Is.SN & Medida angular da inclinação do incisivo superior em relação à base anterior do crânio \\
\hline & MEDIDAS MAXILARES DENTO-ALVEOLARES VERTICAIS \\
\hline 44. Ms-PP & Medida linear da cúspide do primeiro molar superior, perpendicular ao plano palatino (altura dento-alveolar posterior superior) \\
\hline 45. MsA v & Medida linear do ápice da raiz mesial do primeiro molar superior, perpendicular à coordenada Y \\
\hline 46. $\mathrm{MsCr} v$ & Medida linear do centro de resistência do primeiro molar superior, perpendicular à coordenada Y \\
\hline 47. $\mathrm{MsC} v$ & Medida linear da cúspide mésio-vestibular do primeiro molar superior, perpendicular à coordenada Y \\
\hline 48. Is-PP & Medida linear da borda incisal do incisivo central superior, perpendicular ao plano palatino (altura dento-alveolar anterior superior) \\
\hline 49. IsA v & Medida linear do ápice do incisivo central superior, perpendicular à coordenada Y \\
\hline 50. IsCr v & Medida linear do centro de resistência do incisivo central superior, perpendicular à coordenada Y \\
\hline 51. IsI v & Medida linear da borda do incisivo central superior, perpendicular à coordenada $\mathrm{Y}$ \\
\hline & MEDIDAS MANDIBULARES DENTO-ALVEOLARES ÂNTERO-POSTERIORES \\
\hline 52. $\mathrm{MiC} \mathrm{h}$ & Medida linear da cúspide mésio-vestibular do primeiro molar inferior, perpendicular à coordenada X \\
\hline 53. $\mathrm{MiCr} h$ & Medida linear do centro de resistência do primeiro molar inferior, perpendicular à coordenada X \\
\hline 54. MiA h & Medida linear do ápice da raiz mesial do primeiro molar inferior, perpendicular à coordenada X \\
\hline 55. Mi.PM & Ângulo que mede a inclinação do longo eixo (ápice- cúspide) do primeiro molar inferior em relação ao plano mandibular \\
\hline 56. Mi.SN & Ângulo que mede a inclinação do longo eixo (ápice-cúspide) do primeiro molar inferior em relação à base do crânio \\
\hline 57. lil h & Medida linear da borda incisal do incisivo central inferior, perpendicular à coordenada $X$ \\
\hline 58. $\mathrm{liCr} h$ & Medida linear do centro de resistência do incisivo central inferior, perpendicular à coordenada X \\
\hline 59. liA h & Medida linear do ápice do incisivo central inferior, perpendicular à coordenada X \\
\hline 60. li.PM & Ângulo que mede a inclinação do longo eixo (ápice-incisal) do incisivo central inferior em relação ao plano mandibular \\
\hline 61. li.SN & Ângulo que mede a inclinação do longo eixo (ápice incisal) do incisivo central inferior em relação à base do crânio \\
\hline & MEDIDAS MANDIBULARES DENTO-ALVEOLARES VERTICAIS \\
\hline 62. MiA v & Medida linear do ápice da raiz mesial do primeiro molar inferior, perpendicular à coordenada Y \\
\hline 63. MiCr v & Medida linear do centro de resistência do primeiro molar inferior, perpendicular à coordenada Y \\
\hline 64. MiC v & Medida linear da cúspide mésio-vestibular do primeiro molar inferior, perpendicular à coordenada Y \\
\hline 65. liA v & Medida linear do ápice do incisivo central inferior, perpendicular à coordenada $Y$ \\
\hline 66. liCr v & Medida linear do centro de resistência do incisivo central inferior, perpendicular à coordenada Y \\
\hline 67. lil v & Medida linear da borda incisal do incisivo central inferior, perpendicular à coordenada $Y$ \\
\hline
\end{tabular}




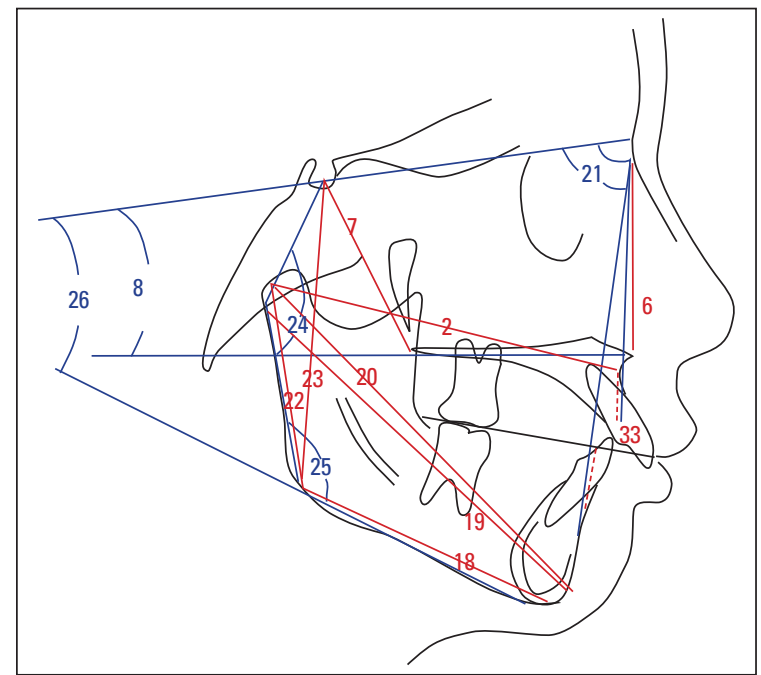

FIGURA 5 - Grandezas cefalométricas tradicionais.

Após demarcação dos pontos cefalométricos, estes foram digitados utilizando um microcomputador IBM compatível ao programa "Dentofacial Planner". Todos os pontos foram digitados sobre uma mesa digitalizadora de marca $\mathrm{Nu}$ monics utilizando-se um programa padrão desenvolvido no Departamento de Ortodontia da "Baylor College of Dentistry" (Fig. 3, Tab. 3). Os ângulos e distâncias foram calculados por este programa e posteriormente analisados. Vinte e cinco grandezas cefalométricas e vinte e um pontos foram selecionados para se avaliar de forma setorizada as respostas em determinadas áreas ou dimensões da face. Para efeito de apresentação dos resultados e discussão, elas foram divididas em deslocamento horizontal e vertical da base óssea maxilar e mandibular, movimentação horizontal e vertical dos molares e incisivos superiores, movimentação horizontal e vertical dos molares e incisivos inferiores e movimento intermaxilar (Tab. 4, Fig. 5 e 6).

Foi utilizado um sistema de análise das respostas de tratamento, em coordenadas, representativo dos movimentos dentários e dos movimentos das bases ósseas, decompondo-os nos seus vetores horizontais e verticais (Fig. 7). Este sistema foi adaptado daquele que tem sido uti-

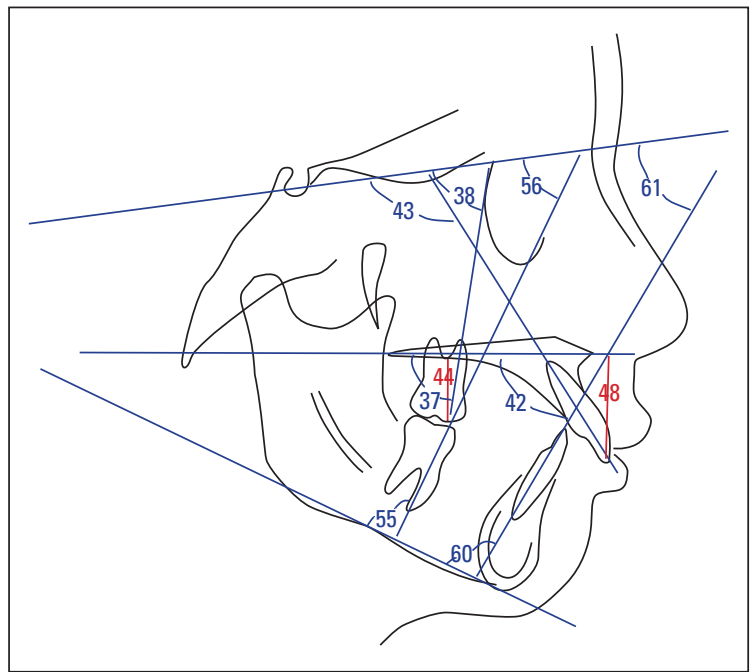

FIGURA 6 - Grandezas cefalométricas tradicionais.

lizado por Peter Buschang no Departamento de Ortodontia do Baylor College of Dentistry. Esta análise é baseada na técnica de superposição de traçados cefalométricos, originalmente desenvolvida por Björk e Skieller ${ }^{5,6}$ que utilizaram implantes metálicos e elaboraram uma representação discriminatória dos movimentos de irrupção dentária, subtraídos do deslocamento espacial total dos dentes, promovidos pelos deslocamentos do crescimento facial a partir da superposição na base do crânio. Assim, superposições de traçados cefalométricos em estruturas estáveis da maxila (Fig. 9) e da mandíbula (Fig. 10), foram consideradas em relação aos dados da superposição total na base anterior do crânio (Fig. 8), com o objetivo de discriminar os movimentos dentários dos movimentos das bases ósseas. Utilizou-se a Linha de Referência da Base do Crânio (Linha que passa pelo ponto Sela determinada menos 7 graus em relação à linha BPC e BAC em T1) com o eixo cartesiano de coordenadas $\mathrm{X}$. O eixo de coordenadas $Y$ utilizado foi obtido pela reta perpendicular ao eixo $\mathrm{X}$ que passava pelo ponto Sela. Vinte e um pontos cefalométricos foram utilizados na obtenção das medidas nas coordenadas X e Y (Fig. 3, Tab. 3). 


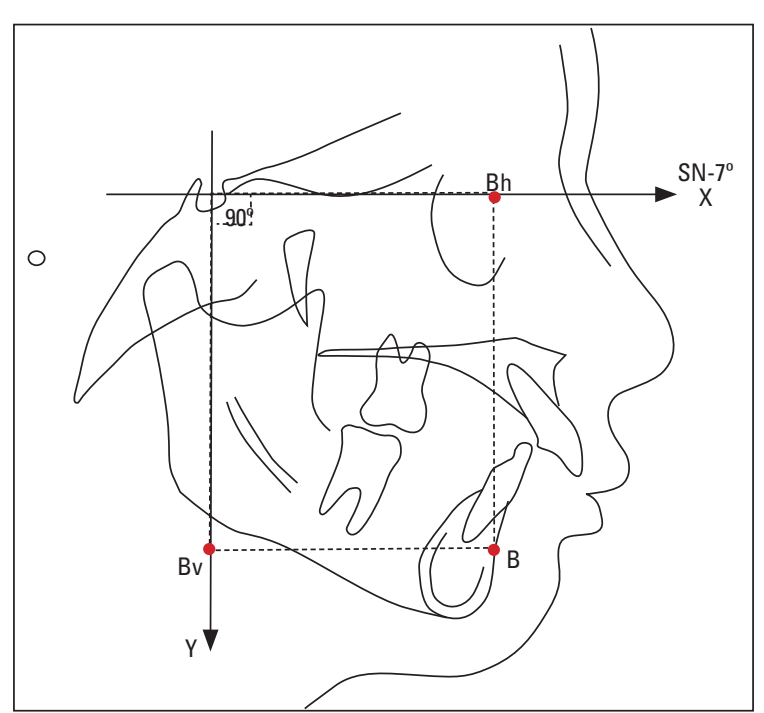

FIGURA 7 - Exemplo de medidas horizontal e vertical de um ponto baseadas nas coordenadas $x$ e $y$.

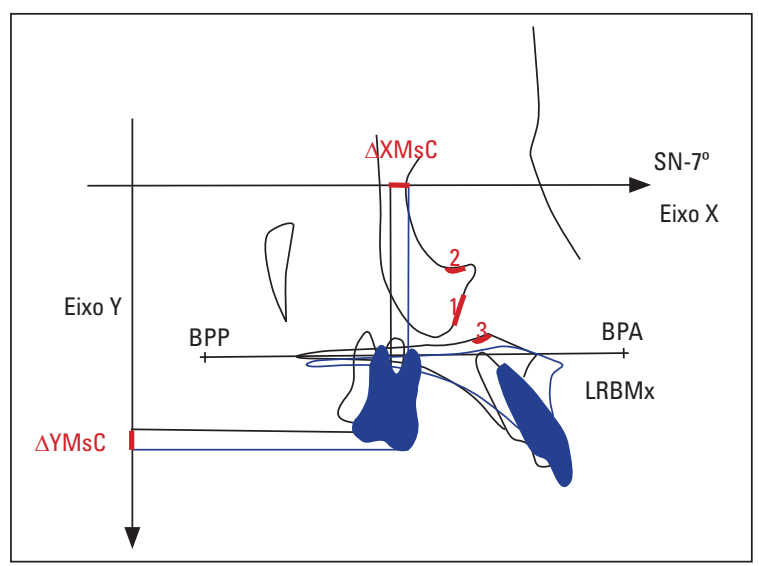

FIGURA 9 - Superposição regional maxilar. 1- Área de registro no contorno anterior do malar; 2- Área de ajuste do traçado no contorno inferior da órbita. 3 - Área de ajuste do traçado no contorno superior do assoalho das fossas nasais. $\triangle \mathrm{XMsC}$ h - Diferencial do mov. horiz. puro da cúspide do molar superior na coord. $\mathrm{X}$. $\triangle \mathrm{YMsC} v$ - Diferencial do mov. vert. puro da cúspide do molar superior na coord.Y

\section{Erro do método cefalométrico}

Dez dos cefalogramas escolhidos ao acaso, perfazendo 20\% da amostra, foram redigitados com o objetivo de se verificar o erro de reprodutibilidade das medidas cefalométricas. Esta verificação

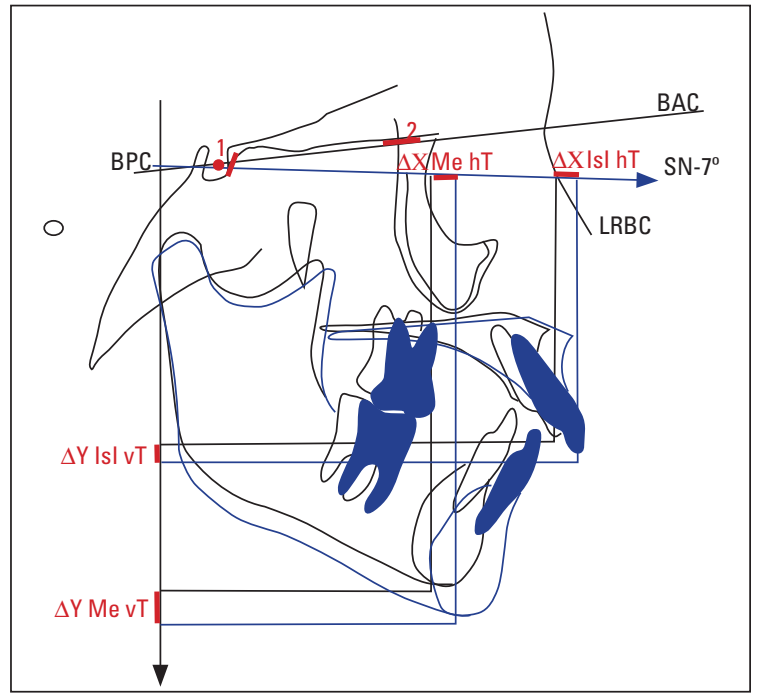

FIGURA 8 - Superposição total na base do crânio. 1- Área de registro ânteroposterior no contorno da Sela; 2- Área de ajuste vertical no soalho da fossa craniana média.

$\Delta \mathrm{XIsI}$ hT - Diferencial do mov. horiz. total da borda do Inc.Sup. na coordenada $\triangle \mathrm{XIMe}$ hT - Diferencial do mov. horiz. total do ponto Mentoniano na coordenada X $\Delta$ YIsI vT - Diferencial do mov. vert. total da borda do Inc.Sup. na coordenada $Y$ $\triangle \mathrm{YMe} v \mathrm{VT}$ - Diferencial do mov. vert. total do ponto Mentoniano na coordenada $Y$

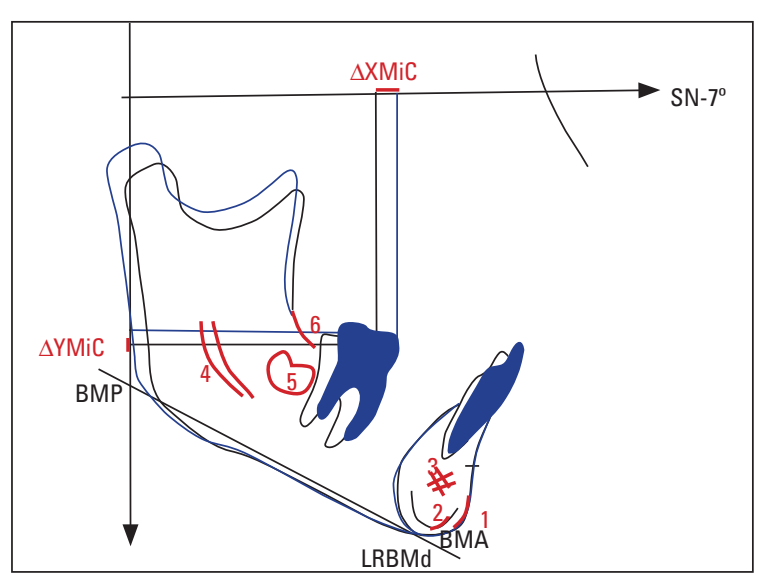

FIGURA 10 - Superposição regional mandibular. Estruturas registros de superposição: 1- Contorno anterior da sínfise. 2- Cortical interna da região inferior da sínfise mentoniana. 3- Estruturas trabeculares no interior da sínfise. 4- Imagens do canal mandibular. 5- Coroas dos terceiros molares. 6- Contorno anterior do ramo ascendente. $\triangle \mathrm{XMiCh}$ - Diferencial do movimento horizontal puro da cúspide mesial do $1^{\circ}$ molar inferior na coordenada X. $\triangle \mathrm{YMiCv}$ - Diferencial do movimento vertical puro da cúspide mesial do $1^{\circ}$ molar inferior na coordenada $Y$.

se deu utilizando-se o método de regressão linear e para verificação de hipóteses do ajuste do modelo à técnica de intervalo de confiança ao nível de probabilidade de $95 \%$ de confiança. Foi ainda aplicada a estatística F de Snedecor para verificar 
o ajuste dos pontos no plano cartesiano do modelo de regressão linear.

\section{Planejamento Estatístico}

Empregou-se a estatística t-Student para as comparações entre os grupos Favorável (F) e Desfavorável (D) quanto:

1) À magnitude média das medidas cefalométricas empregadas.

2) Ao deslocamento médio horizontal ou vertical da base maxilar e da base mandibular.

3) À movimentação total esquelética e dentária na direção horizontal ou vertical dos molares e incisivos superiores e inferiores.

\section{RESULTADOS E DISCUSSÃO}

A utilização do aparelho extrabucal de Kloehn como forma de controle e modificação da relação maxilo-mandibular e/ou dentária, em desarmonia nos casos de Classe II, popularizou-se entre os clínicos, tornando-se um dos mais importantes recursos disponíveis para a sua correção.

Com o avanço dos meios de diagnóstico e avaliação das alterações presentes na Classe II promovidos pelo aparelho extrabucal de Kloehn (cefalometria radiográfica), tornou-se clara a necessidade de se levar em consideração o padrão de crescimento ou o tipo facial que o indivíduo apresenta. Porém poucos estudos foram realizados neste sentido e quando o foram, não apresentaram metodologia adequada ou não levaram em consideração a análise dos erros que acometem qualquer conjunto de mensurações.

O presente estudo foi do tipo retrospectivo e utilizou uma técnica de superposição cefalométrica que permite uma avaliação criteriosa da resposta cefalométrica promovida pelo tratamento ministrado, decompondo-a em seus componentes horizontais e verticais ${ }^{5,6,11}$.

A anualização da quantidade de deslocamento apresentada pelas estruturas esqueléticas maxilo-mandibulares e a quantidade de movimento dentário durante o crescimento craniofacial normal sob influência do aparelho extrabucal de Kloehn e aparelho fixo edgewise convencional representam outro refinamento metodológico deste trabalho e têm sido pouco incorporados na literatura ${ }^{5,6,13,14,25,33}$.

O tempo médio de tratamento nesta pesquisa foi de 3,6 anos (desvio padrão de 1,30) para o grupo favorável e de 3,4 anos (desvio padrão de 1,05) para o grupo desfavorável.

Uma limitação verificada no presente estudo foi a falta de grupo controle próprio para comparação dos valores cefalométricos experimentais. A utilização de grupo controle apropriado, isto é, de pacientes com Classe II, sem tratamento, é relativamente raro $^{26,31,35,42,43}$. As conclusões de investigações sem grupo controle ficam muito limitadas, porque não se identifica claramente o que foi resposta de tratamento da mudança natural promovida pelo crescimento ${ }^{4,9,13,14,15,25}$.

$\mathrm{Na}$ presente investigação deveriam ter sido incluídos dois grupos controle, ao invés de um, uma vez que foram estabelecidos dois grupos experimentais baseados no padrão facial, o que não é impossível de ser obtido, mas representa mais um grau de dificuldade. Os recentes avanços na área da bioética podem ser apontados como mais uma barreira para identificar pacientes com uma determinada característica, diagnosticar o problema e deixar para tratá-los mais tarde, baseados na necessidade de controle experimental.

Considerou-se que a hipótese de trabalho não envolveria a comparação dos grupos experimentais com os grupos controles pelo fato de já existirem estudos experimentais que utilizaram um agrupamento de Classes II no próprio departamento ${ }^{13,14,15,25}$. Assim, para servir como dados de comparação na discussão, foram utilizados os resultados das investigações de Goldreich ${ }^{15}$, Martins $^{25}$, Gandini ${ }^{14}$ e Gandini Jr. ${ }^{13}$, que derivam da mesma amostra.

Um dos aspectos interessantes incorporados à investigação foi o de que se caracterizou inicialmente os grupos experimentais através de 


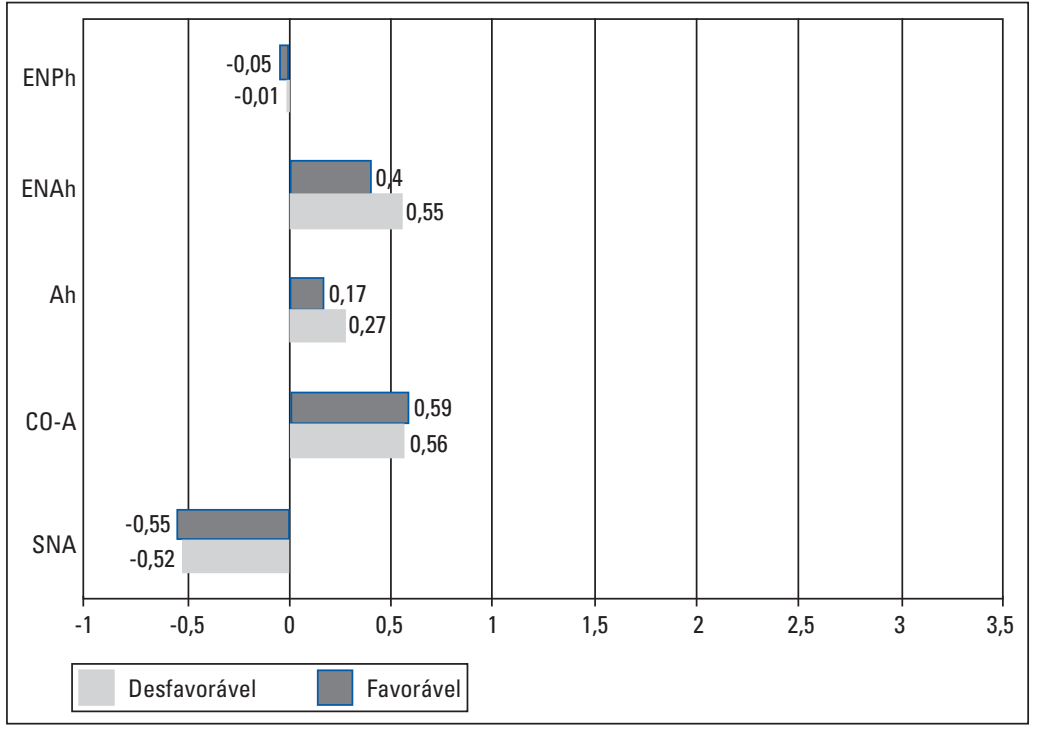

FIGURA 11 - Gráfico do deslocamento horizontal da base maxilar. muitas outras investigações já publicadas ${ }^{1,2,3,7,27,35,41,43}$.

Estatisticamente, a ação do aparelho extrabucal de Kloehn sobre o comprimento maxilar foi semelhante entre os grupos favorável e desfavorável, o que foi comprovado nesta investigação pela alteração na medida Co-A, de 0,59 mm/ano (F) e $0,56 \mathrm{~mm} / \mathrm{ano}$ (D). Com o crescimento normal, esta dimensão sofreu um aumento expressivo, conforme foi mostrado por $\mathrm{Ursi}^{41}$ que reportou um valor de 2,85 mm/ano; Goldreich ${ }^{15}$ de 1,04 mm/ano; Martins ${ }^{25}$ de 1,59 mm/ano e Gandini Jr. ${ }^{13}$ de $1,89 \mathrm{~mm} / \mathrm{ano}$. Esta informação reforça a ação restritiva do aparelho extrabucal sobre o crescimento maxilar, reduzindo seu comprimento em 3 a 4 vezes o esperado com o crescimento natural.

Os valores para a medida do ângulo SNA de 0,55 graus/ano (F) e 0,52 graus/ano (D) e para o SNB de 0,12 graus/ano (F) e 0,29 graus/ano (D) mostraram que houve poucas modificações esqueléticas intermaxilares. Os valores normais para o SNB na Classe II, sem tratamento, mostrados por Goldreich ${ }^{15}$ foram um aumento de 0,47 graus/ano para o SNB. Martins ${ }^{25}$ reportou uma variação de 0,29 graus/ano para o SNB, enquanto Gandini Jr. ${ }^{13}$ verificou que o SNB apresentava um aumento de 0,51 graus/ano e Gandini ${ }^{14}$ encontrou valores para o SNB de 0,89 graus/ano. Estes dados indicam que a mandíbula não apresentou o deslocamento anterior que seria de se esperar com o crescimento normal, efeito colateral do extrabucal de Kloehn não desejado em casos de discrepância maxilomandibular presente na Classe II. No grupo favorável, houve um aumento inexpressivo do SNB, enquanto que no grupo desfavorável este valor foi um pouco superior, achado contrário ao esperado, mas que pode ser explicado pela tendência a uma 


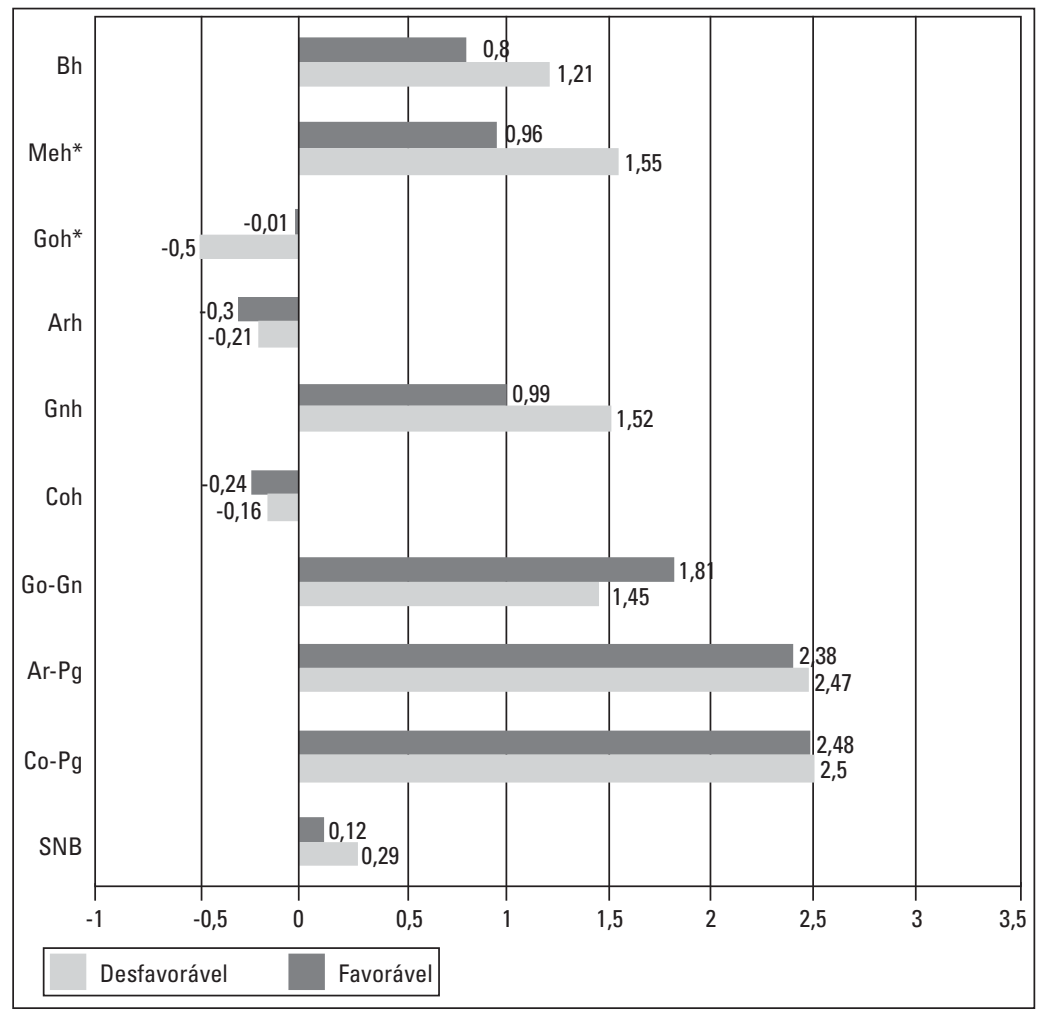

FIGURA 12 - Gráfico do deslocamento horizontal da base mandibular.

nha sido mostrado variando de $1,04 \mathrm{~mm} /$ ano até $1,5 \mathrm{~mm} / \mathrm{ano}$ por Martins $\mathrm{s}^{25}$ e $1,89 \mathrm{~mm} / \mathrm{ano}$ por Gandini Jr. ${ }^{13}$. Com relação à medida $\mathrm{Co}-\mathrm{Pg}$, o aumento observado de $2,48 \mathrm{~mm} /$ ano $(\mathrm{F})$ e 2,50 mm/ano (D) está dentro da variação esperada para esta dimensão com o crescimento normal na Classe II sem tratamento, segundo Martins ${ }^{25}$ de $2,80 \mathrm{~mm} / \mathrm{ano}$ para a medida Co-Gn.

Outro dado que reforça o menor deslocamento mandibular para anterior pode ser visto na figura 12 onde se verifica que o ponto $\mathrm{B}$ se desloca na horizontal 0,80 mm/ano (F) e $1,21 \mathrm{~mm} /$ ano (D), quando deveria ter aumentado $1,74 \mathrm{~mm} /$ ano segundo Goldreich ${ }^{15}$ e 1,26 mm/ano segundo Martins ${ }^{25}$, na Classe II, divisão 1 , sem tratamento.

rotação horária mandibular, verificada no grupo favorável (SN.PM de 0,09) e rotação anti-horária no grupo desfavorável (SN.PM de $-0,15$ ), resultado da ação do aparelho extrabucal de Kloehn. Este resultados estão de acordo com Hubbard et al. ${ }^{19}$ e divergindo de autores que não observaram alteração no ângulo SNB, tais como Sandusky ${ }^{40}$, Mills et al. ${ }^{30}$ e Cangialosi ${ }^{9}$.

Assim, a relação maxilo-mandibular, avaliada pela medida $\mathrm{AO}-\mathrm{BO}$, exibiu uma melhora, redução de $0,4 \mathrm{~mm} /$ ano em ambos os grupos, mais por conta da restrição do movimento para anterior do ponto A que por um deslocamento anterior do ponto B. Esta restrição do movimento anterior do ponto $\mathrm{A}$ pode ser confirmada também pelo menor aumento esperado da medida Co-A, de 0,59 mm/ano (F) e $0,56 \mathrm{~mm} /$ ano (D), em relação ao valor normal para esta medida que é de $1,5 \mathrm{~mm} / \mathrm{ano}$ em pacientes portadores de Classe II sem tratamento, embora te-
Os pontos Me e Go apresentaram valores estatisticamente diferentes entre os dois grupos. No grupo favorável, o ponto Me deslocou para anterior em menor quantidade em relação ao grupo desfavorável, respectivamente $0,96 \mathrm{~mm} /$ ano e 1,55 $\mathrm{mm} / \mathrm{ano}$. Por outro lado, o ponto Go apresentou deslocamento para posterior maior no grupo desfavorável de $0,50 \mathrm{~mm} /$ ano em relação ao favorável de $0,01 \mathrm{~mm} /$ ano. $\mathrm{O}$ deslocamento destes pontos acompanha a tendência observada de aumento do comprimento do corpo mandibular avaliado pela medida Go-Gn, de 1,81 mm/ano no grupo favorável e de 1,45 mm/ano no grupo desfavorável.

Os pontos Ar e Co deslocaram-se para posterior, respectivamente $0,30 \mathrm{~mm} /$ ano e 0,24 $\mathrm{mm}$ /ano no grupo favorável e $0,21 \mathrm{~mm} / \mathrm{ano}$ e $0,16 \mathrm{~mm} /$ ano e no grupo desfavorável, e para baixo, respectivamente $0,75 \mathrm{~mm} /$ ano e $0,53 \mathrm{~mm} /$ ano no grupo favorável e $0,75 \mathrm{~mm} /$ ano 


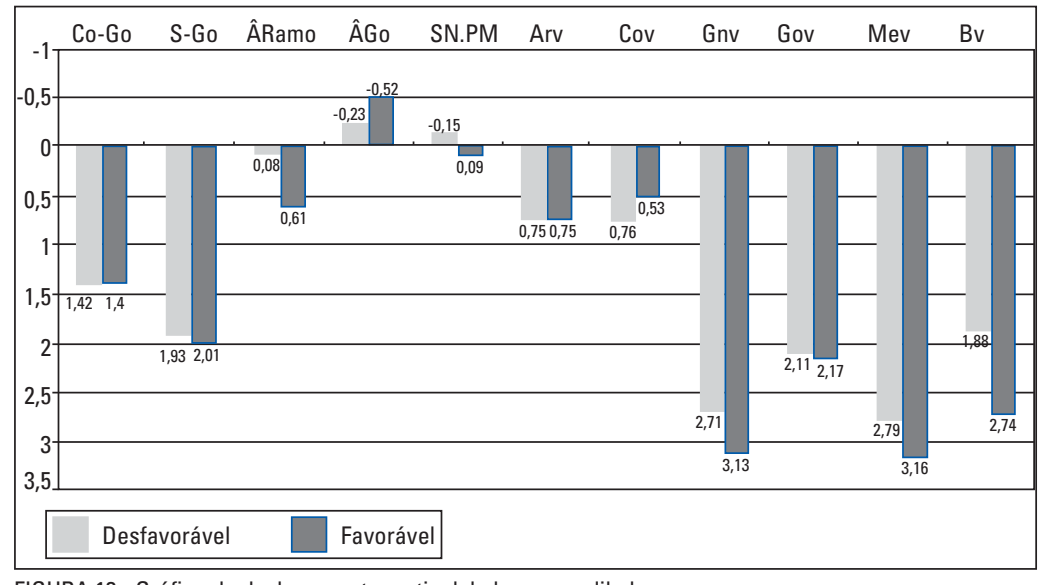

FIGURA 13 - Gráfico do deslocamento vertical da base mandibular.

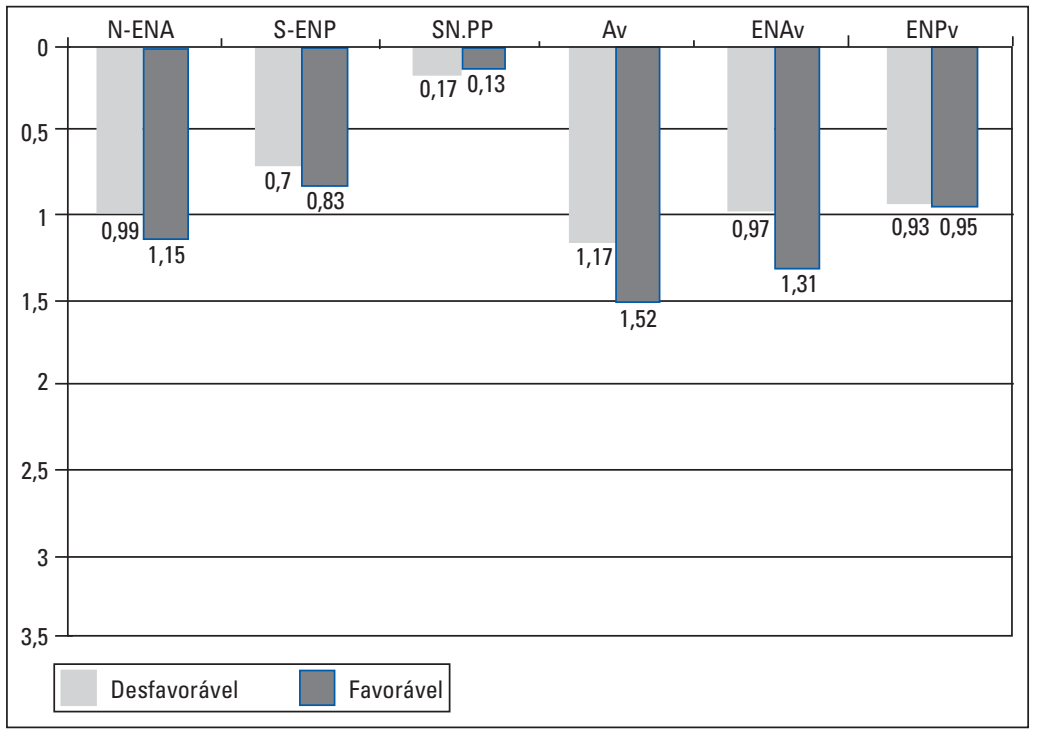

FIGURA 14 - Gráfico do deslocamento vertical da base maxilar.

e 0,76 mm/ano no grupo desfavorável, indicando assim que houve um deslocamento da fossa glenóide para baixo e uma certa estabilidade no sentido ântero-posterior, conforme relatado por Martins ${ }^{25}$.

A medida SN.PM indicou haver uma estabilidade da inclinação do plano mandibular com tendência a fechar nos casos desfavoráveis e abrir nos casos favoráveis. Esta tendência pôde ser verificada, também, pela descida dos pontos $\mathrm{B}$ de $2,74 \mathrm{~mm} /$ ano (F) e 1,88 mm/ano (D), Gn de $3,13 \mathrm{~mm} /$ ano (F) e 2,71 mm/ano (D), Go de 2,17 mm/ano (F) e
2,11 mm/ano (D), Me de 3,16 $\mathrm{mm} / \mathrm{ano}(\mathrm{F})$ e $2,79 \mathrm{~mm} / \mathrm{ano}$ (D) (Fig. 13).

A maior inclinação do plano mandibular que ocorreu no grupo favorável está relacionada à maior extrusão dos primeiros molares superiores, de $2,13 \mathrm{~mm} /$ ano ao nível da cúspide mésio-vestibular, enquanto que a redução da inclinação do plano mandibular no grupo desfavorável relaciona-se à menor quantidade de extrusão do primeiro molar superior, verificada neste grupo, de 1,82 mm/ano. Estes resultados indicaram que houve uma preocupação do profissional no controle da movimentação dos molares superiores, menor tanto no sentido vertical como no horizontal. Verificou-se um menor movimento distal dos molares superiores no grupo desfavorável de $0,52 \mathrm{~mm} / \mathrm{ano}$ quando comparado ao favorável de $0,02 \mathrm{~mm} / \mathrm{ano}$.

Tem sido apontado por alguns autores que a rotação do plano palatino, no sentido horário, soma-se à extrusão dos incisivos superiores e à exposição de gengiva no sorriso ao final do tratamento, o que pode proporcionar uma resposta de tratamento desagradável ${ }^{2,11,19,22,29,30,32,38,40}$.

A presente investigação mostrou que não houve uma diferença na mudança do plano palatino entre os grupos, havendo diferença entre os grupos na quantidade de extrusão dos molares, mas não na dos incisivos.

Este resultado pode ser verificado inicialmente na figura 14 pela semelhante proporção de deslocamento para baixo dos pontos ENA, ENP, 


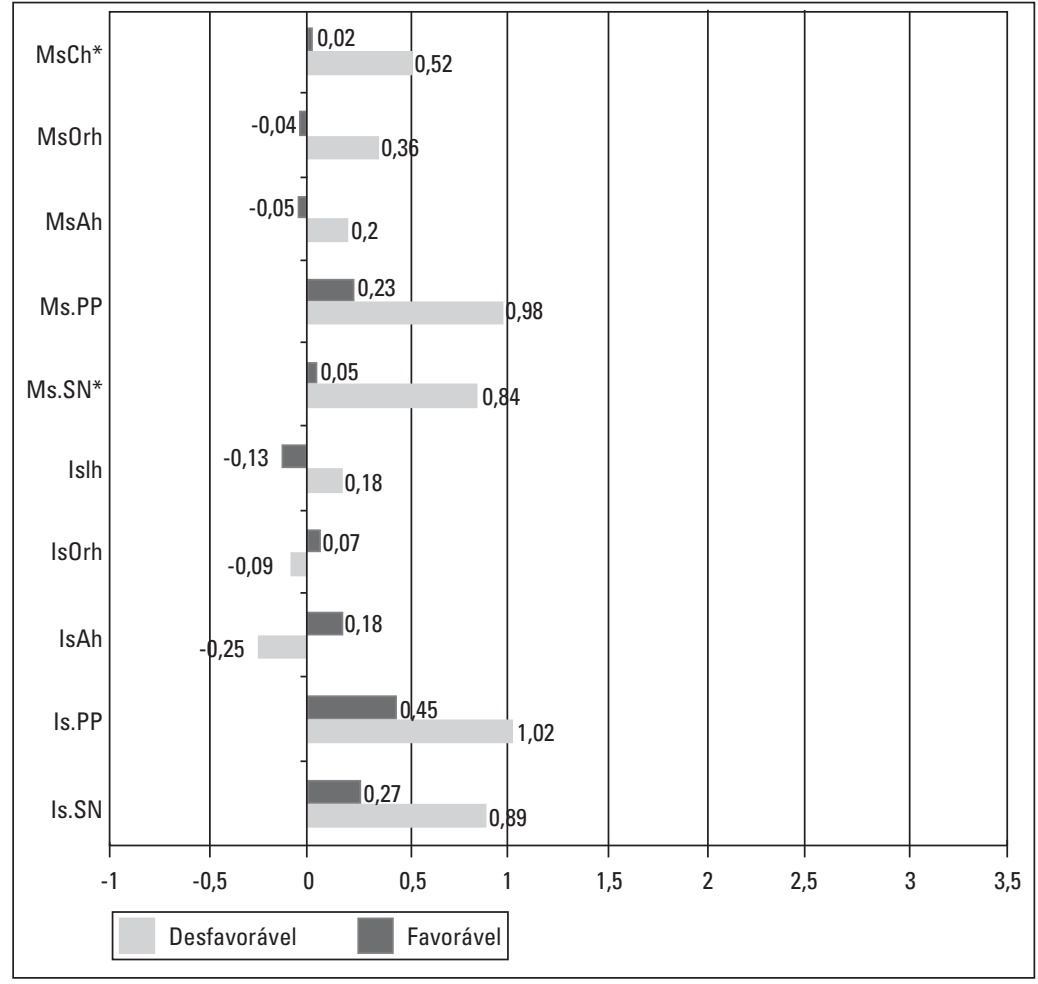

FIGURA 15 - Gráfico da movimentação horizontal total dos molares e incisivos superiores. ficantemente, ocorrendo uma movimentação de 0,13 graus/ ano $(\mathrm{F})$ e 0,17 graus/ano (D), reforçado pelo abaixamento proporcional da ENA e ENP já relatados. Estes achados foram semelhantes aos valores observados para a Classe II sem tratamento, encontrados por outros autores como Ursi ${ }^{41}$, de 0,83 graus/ano; Goldreich ${ }^{15}$, de -0,33 graus/ano; Martins ${ }^{25}$, de 0,04 graus/ano, e Gandini Jr. ${ }^{13}$, de 0,08 graus/ano.

A medida linear de S-ENP apresentou valores de 0,83 $\mathrm{mm} / \mathrm{ano}(\mathrm{F})$ e $0,70 \mathrm{~mm} / \mathrm{ano}$ (D), assim como os da N-ENA de $1,15 \mathrm{~mm} /$ ano (F) e 0,99 $\mathrm{mm} / \mathrm{ano}$ (D) mostraram-se semelhantes entre si, evidenciando novamente que ocorreu deslocamento proporcional da base maxilar, enquanto que a base mandibular, observada pela variável SN.PM, evidenciou apresentar uma leve tendência à rotação horária nos casos favoráveis de 0,09 graus/ano e uma leve rotação antihorária nos casos desfavoráveis de 0,15 graus/ano, diferença esta significativa na comparação entre os grupos.

Uma das grandes críticas que se faz à utilização do aparelho extrabucal de Kloehn é a extrusão dos molares superiores, o que proporcionaria ainda uma abertura do plano mandibular, principalmente nos casos desfavoráveis. A ação de uma força cervical que, decomposta, exibe um componente de extrusão dos molares e uma outra força de distalização que passa por baixo do centro de resistência da maxila promoveria a rotação no sentido horário do plano palatino e abertura do plano mandibular.

$\mathrm{Na}$ presente investigação, o tratamento da Classe II, divisão 1, com o aparelho extrabucal do tipo Kloehn mostrou não promover diferença estatisti- 


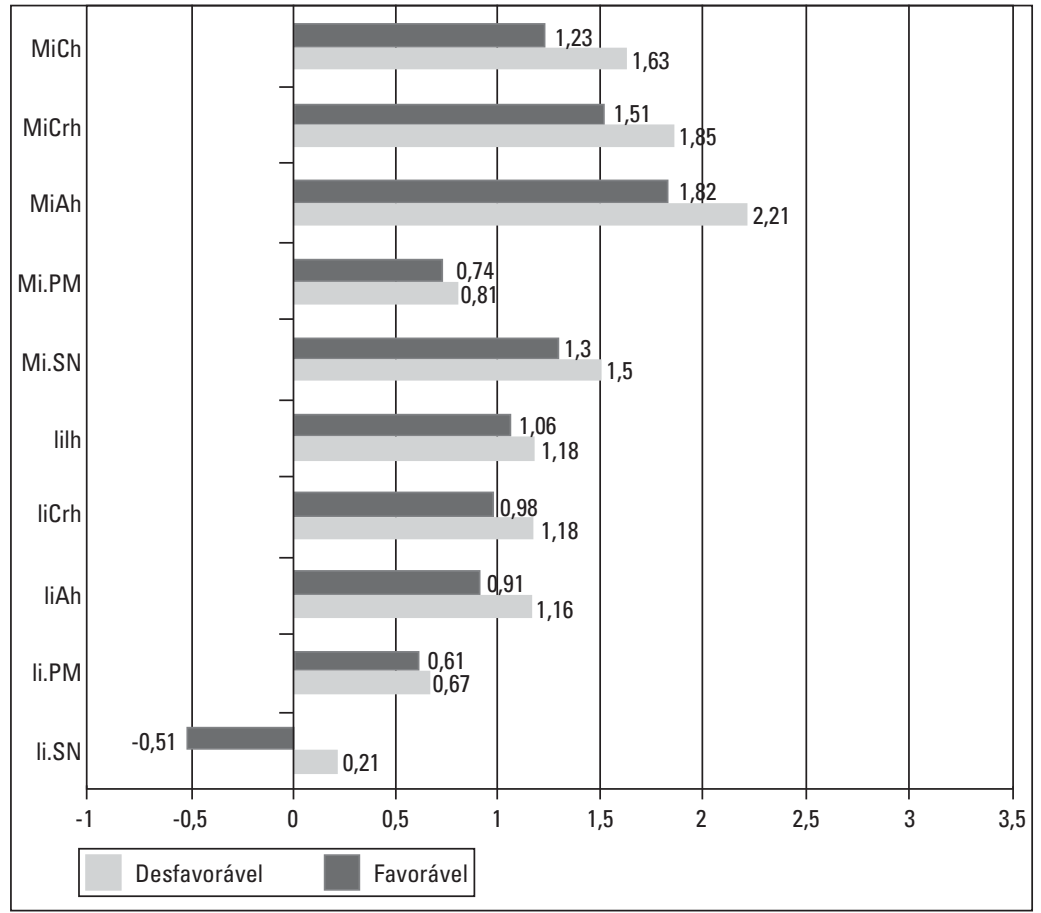

FIGURA 16 - Gráfico da movimentação horizontal total dos molares e incisivos inferiores.

com inclinação menor do molar, Ms.SN de 0,05 graus/ano e no grupo desfavorável $\mathrm{MsCh}$ de $0,52 \mathrm{~mm} /$ ano e Ms.SN de 0,84 graus/ano. Esta mesialização de $0,52 \mathrm{~mm} /$ ano (D) favoreceu a não abertura do padrão facial como seria esperado nos casos de padrão desfavorável. Isto deixa evidente que o tratamento ortodôntico influenciou o posicionamento dos primeiros molares superiores, uma vez que estes dentes deveriam exibir um padrão de movimentação mesial com o crescimento natural, conforme demonstrado por Goldreich $^{15}$ de 1,38 mm/ano, por Martins $^{25}$ de 1,47 mm/ano, e por Gandini Jr. ${ }^{13}$ de 0,45 mm/ano. Outras investigações apresentam as mesmas observações em re-

camente significante entre os dois grupos tratados em relação à movimentação vertical dos molares superiores, embora tenha sido mais evidente no grupo favorável em relação à cúspide mésio-vestibular de $2,13 \mathrm{~mm} /$ ano do que no desfavorável de $1,82 \mathrm{~mm} /$ ano. Os dados da literatura mostram haver uma maior tendência de extrusão dos molares superiores durante o tratamento com o aparelho extrabucal de Kloehn",8,9,16,17,26,32,40. Por outro lado, semelhante padrão de movimentação vertical dos molares superiores foi observado em pacientes portadores de Classe II sem tratamento, tal como o verificado por Goldreich ${ }^{15}$, de 1,23 mm/ano, por Martins $^{25}$, de 1,85 mm/ano e por Gandini Jr. ${ }^{13}$, de $1,58 \mathrm{~mm} /$ ano.

Nos dois grupos estudados (Fig. 15) ocorreram alterações dento-alveolares no sentido horizontal, particularmente dos primeiros molares superiores com diferença estatisticamente significante entre os grupos. No grupo favorável evidenciou-se uma restrição mesial maior, $\mathrm{MsCh}$ de 0,02 mm/ano, lação aos primeiros molares superiores quanto a sua mesialização $0^{9,19,30}$.

A influência do tratamento sobre os dentes anteriores no sentido horizontal mostrou ocorrer uma inclinação axial dos incisivos superiores para vestibular em relação ao plano palatino, Is.PP de 0,45 graus/ano (F) e 1,02 graus/ano (D), e à base do crânio 0,27 graus/ano (F) e 0,89 graus/ano (D). Os valores normais para a diferença anual do ângulo Is.SN em paciente Classe II, sem tratamento, foi de 0,53 graus/ano para Ursi ${ }^{41}, 0,89$ graus/ano para Goldreich $^{15},-0,07$ graus/ano para Martins ${ }^{25},-0,35$ graus/ano para Gandini Jr. ${ }^{13}$.

Observou-se na figura 16 que os primeiros molares inferiores exibiram uma tendência de inclinação distal em relação à base do crânio, Mi.SN de 1,3 graus/ano (F) e 1,50 graus/ano (D) e ao plano mandibular, Mi.PM de 0,74 graus/ano (F) e 0,81 graus/ano (D), sendo mais evidente no grupo desfavorável.

Nos dois grupos estudados os incisivos inferiores 


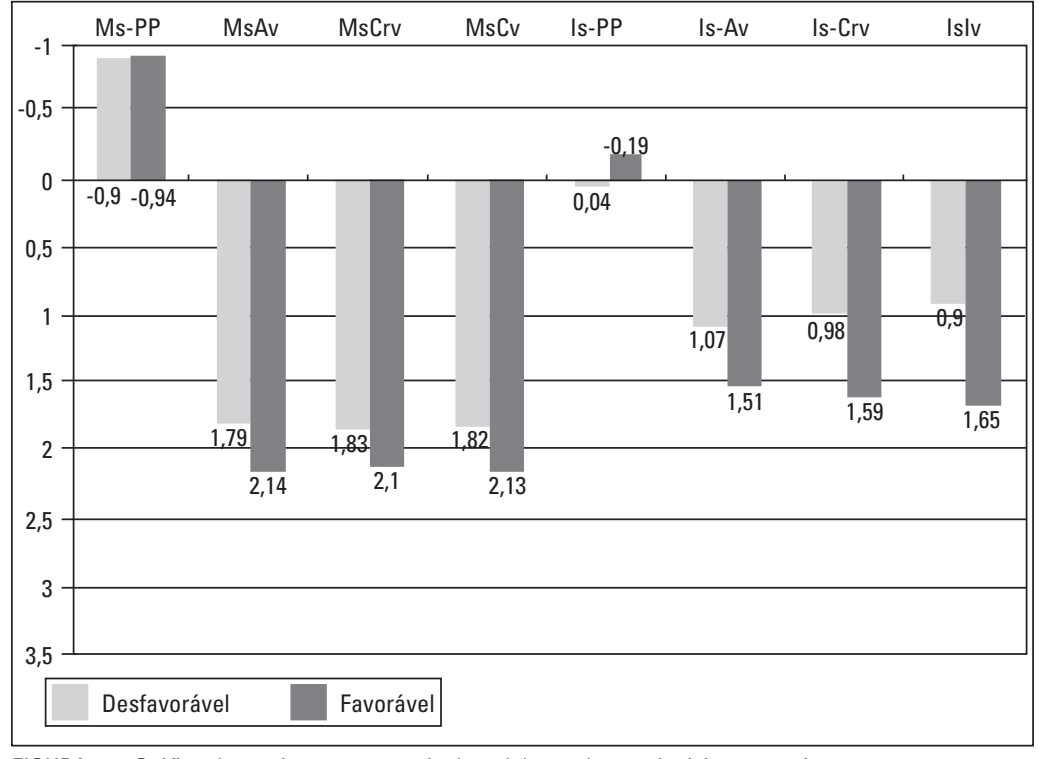

FIGURA 17 - Gráfico da movimentação vertical total dos molares e incisivos superiores.

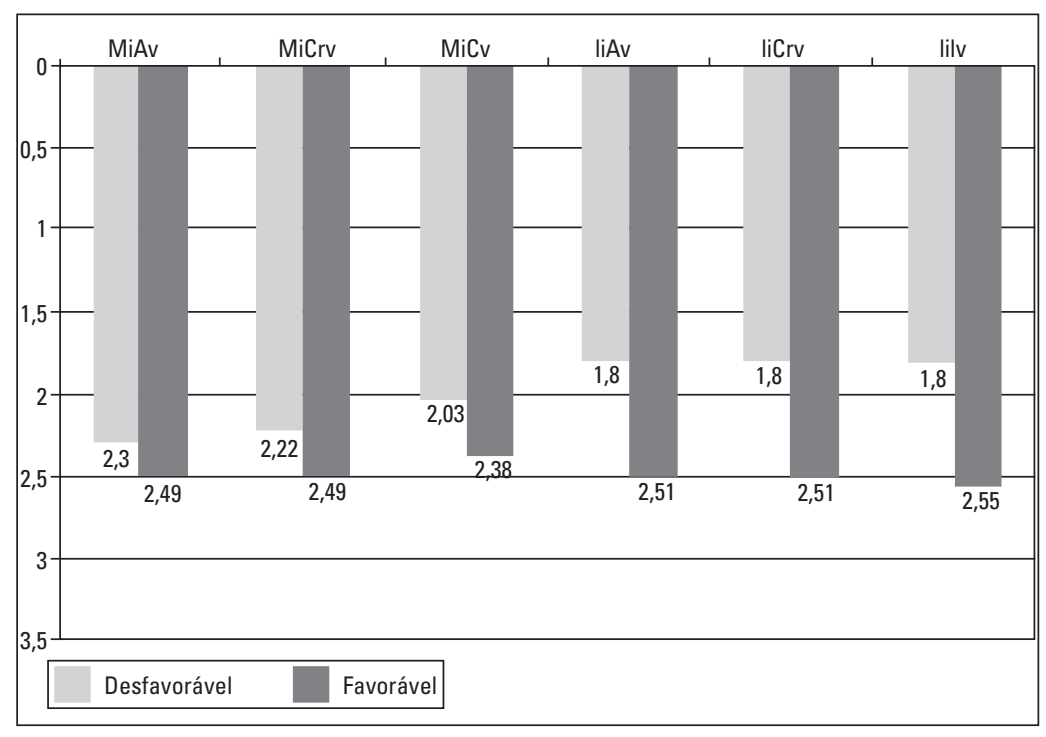

FIGURA 18 - Gráfico da movimentação vertical dos molares e incisivos inferiores.

deslocaram-se ligeiramente para vestibular em relação ao plano mandibular, Ii.PM de 0,61 graus/ano (F) e de 0,67 graus/ano (D). No grupo favorável os incisivos inferiores deslocaram-se para lingual em relação à base do crânio, Ii.SN de 0,51 graus/ano, enquanto que no grupo desfavorável foi no sentido oposto, de 0,21 graus/ano.

Houve uma restrição da erupção dentária no arco inferior que normalmente ocorreria durante o crescimento normal, conforme relatado por Martins ${ }^{25}$, provavelmente pela ação do aparelho fixo edgewise utilizado. Aplicando-se o $\mathrm{t}$ de Student nas variáveis que representam o movimento vertical de incisivos e molares, verificou-se que os valores encontrados não eram significativos com $\mathrm{p}$ maior que 0,05 , não rejeitando, assim, a hipótese de que fossem diferentes de 0 . $\mathrm{O}$ movimento vertical e ântero-posterior dos incisivos e molares inferiores foi mínimo e em direção oposta ao deslocamento anterior promovido pela base óssea mandibular (Fig. 17 e 18).

\section{CONCLUSÕES}

No geral não houve diferença significativa na resposta cefalométrica promovida pelo tratamento da Classe II, divisão 1, com o aparelho extrabucal de Kloehn associado ao aparelho fixo edgewise, quando considerados os padrões faciais favorável e desfavorável segundo índice cefalométrico de Jarabak.

O aparelho extrabucal de Kloehn associado ao aparelho fixo edgewise promoveu uma restrição do deslocamento anterior da maxila e um menor deslocamento anterior da mandíbula associado a uma leve abertura do ângulo do plano mandibular nos casos favoráveis e um leve fechamento deste ângulo nos casos desfavoráveis.

O aparelho extrabucal de Kloehn associado ao aparelho fixo edgewise promoveu uma restrição do movimento mesial, e um deslocamento 
inferior (extrusão) dos molares superiores, mais evidente no grupo favorável, maior e em direção oposta ao promovido pelo deslocamento da base óssea maxilar.

Os incisivos superiores apresentaram uma leve inclinação vestibular e um deslocamento lingual, maiores no grupo desfavorável, em direção oposta ao deslocamento promovido pela base óssea maxilar e um deslocamento vertical mínimo.

O movimento anterior e vertical dos mola- res inferiores foi mínimo e em direção oposta ao deslocamento anterior promovido pela base óssea mandibular pela ação do aparelho fixo edgewise.

O movimento vertical e ântero-posterior dos incisivos inferiores foi mínimo e em direção oposta ao deslocamento anterior da base óssea mandibular pela ação do aparelho fixo edgewise.

\title{
Cephalometric evaluation of Angle Class II division 1 treatment with Kloehn extraoral and edgewise fixed appliance: Facial pattern influence
}

\begin{abstract}
The aim of the present study was to evaluate the cephalometric response to Kloehn extraoral associated to fixed appliances treatment. Initial cephalometric radiographs (T1) and final ones (T2) of two groups composed by 30 patients were selected according to Jarabak index as favorable (hypodivergent) and unfavorable (hyperdivergent). The mean age on the beginning of the treatment was 11.03 years and the final mean age was 14.72, with a mean treatment time of 3.6 years for the favorable group. In the unfavorable group, the initial age was of 11.51 years, and the final age of 15.17, with a mean treatment time of 3.4 years. It was used a X and Y coordinated system to response analysis, representing the dental and skeletal bases movement. The results and treatment responses were analyzed and the favorable and unfavorable groups compared using the t-Student test. There were no statistically significant differences in the cephalometric response of Kloehn extraoral associated to fixed appliances treatment between the two groups. The treatment promoted a restriction of the anterior displacement of maxillary base and a lesser mandibular anterior displacement. Considering the upper teeth movement, there was restriction of the mesial and extrusive movement of the upper molars in the favorable group while the lower teeth movement was minimum on the anterior and vertical sense.
\end{abstract}

Key words: Cephalometrics. Class II. Extraoral. Kloehn.

\section{REFERÊNCIAS}

1. ARAÚJO, M. C. M. Contribuição para análise cefalométricoradiográfica dos critérios da classificação de Angle nos casos de classe I e classe II, divisão 1. 1967. 123 f. Dissertação (Mestrado-Concurso de Cátedra)-Faculdade de Odontologia, Universidade Estadual de Campinas, Piracicaba, 1967.

2. BARTON, J. J. High-pull headgear versus cervical traction: a cephalometric comparison. Am J Orthod, St. Louis, v. 62, p. 517-529, 1972.

3. BAUMRIND, S. et al. Distal displacement of the maxilla and the upper first molar. Am J Orthod, St. Louis, v. 75, p. 630-640, 1979.

4. BAUMRIND, S. et al. Changes in facial dimensions associated with the use of forces to retract the maxilla. Am J Orthod, St. Louis, v. 80, p. 17-30, 1981.

5. BJÖRK, A.; SKIELLER, V. Postnatal growth and development of the maxillary complex. In: McNAMARA Jr., A. (Ed.). Factors affecting the growth of midface. Ann Arbor: University of Michigan, 1976. p. 61-99. Monograph, 6. 
6. BJÖRK, A.; SKIELLER, V. Normal and abnormal growth of mandibular. A synthesis of longitudinal cephalometric implant studies over a period of 25 years. Eur J Orthod, London, v. 5 , p. $1-46,1983$

7. BOECLER, P. R. et al. Skeletal changes associated with extraoral appliance therapy: an evaluation of 200 consecutively treated cases. Angle Orthod, Appleton, v. 59, p. 263-270, 1989

8. BROWN, P. A cephalometric evaluation of high-pull molar headgear and face bow neck strap therapy. Am J Orthod St. Louis, v. 74, p. 621-632, 1978.

9. CANGIALOSI, T. J. et al. A cephalometric appraisal of edgewise class II nonextraction treatment with extraoral force. Am J Orthod Dentofacial Orthop, St. Louis, v. 93, p. 315-324, 1988

10. DE MARSHALL, W. A. Growth and secondary sexual development and related abnormalities. Clin Obstetr Gynecol, Hagerstown, v. 1, p. 593, 1974.

11. DOPPEL, D. M. et al. An investigation of maxillary superimposition techniques using metallic implants. Am J Orthod Dentofacial Orthop, St. Louis, v. 105, p. 161-168, 1994

12. DRELICH, R. C. A cephalometric study of untreated class II, division 1 malocclusion. Angle Orthod, Appleton, v. 18 p. 70-75, 1948.

13. GANDINI JÚNIOR, L. G. Avaliação cefalométrica do tratamento da classe II divisão $1 \mathrm{com}$ aparelho extrabucal de Kloehn e aparelho fixo. 1997. 237 f. Tese (Doutorado em Ortodontia)-Faculdade de Odontologia de Araraquara, Universidade Estadual Paulista, Araraquara, 1997.

14. GANDINI, M. R. E. A. S. Componentes da correção da má-oclusão de Classe II, divisão 1, tratada com aparelho extrabucal de Kloehn, e aparelho fixo. 1997. 141f. Dissertação (Mestrado em Ortodontia)-Faculdade de Odontologia de Araraquara, Universidade Estadual Paulista, Araraquara, 1997.

15. GOLDREICH, H. N. The effects of a modified maxillary splint combined with a highpull headgear. 1994. Citation (Master of Science)-Baylor University, Dallas, 1994.

16. GREGORAK, W. Eruption path of permanent maxillary molars in class II, division 1 malocclusion using headgear. Am J Orthod, St. Louis, v. 8, p. 367-381, 1962

17. HENRIQUES, J. F. C. Estudo cefalométrico comparativo, de três tipos de ancoragem extrabucal, sobre as estruturas dentoesqueléticas, em pacientes com classe II, $\mathbf{1}^{\text {a }}$ divisão. 1993. 166 f. Tese (Livre Docência)-Faculdade de Odontologia de Bauru, Universidade de São Paulo, Bauru, 1993.

18. HENRY, R. G. Indications for early orthodontic treatment. N Z Dent J, Wellington, v. 54, p. 11-15, 1958

19. HUBBARD, G. W.; NANDA, R. S.; CURRIER, F. A cephalometric evaluation of nonextraction cervical headgear treatment in class II malocclusions. Angle Orthod, Appleton, v. 64, p. 359-370, 1994.

20. HUNTER, W. S. The vertical dimensions of the face and skeletodental retrognathism. Am J Orthod, St. Louis, v. 53, p. 586-595, 1967.

21. JAKOBSSON, S. O. Cephalometric evaluation of treatment effects on class II, division 1 malocclusions. Am J Orthod, St. Louis, v. 53, p. 446-457, 1967.

22. KLEIN, P. L. An evaluation of cervical traction on maxilla and the upper first permanent molar. Angle Orthod, Appleton, v. 27, p. $61-68,1957$.

23. KNIGHT, H. The effects of three methods of orthodontics appliance therapy on some commonly used cephalometric angular variables. Am J Orthod Dentofacial Orthop, St. Louis, v. 93, p. $237-244,1988$.

24. McNAMARA JR., J. A. Components of class II malocclusion in children 8-10 years of age. Angle Orthod, Appleton, v. 51, p. 177-202, 1981.
25. MARTINS, J. C. R. Avaliação cefalométrica comparativa dos resultados da interceptação da má oclusão de classe II, divisão 1a, de Angle, obtidos com o aparelho extrabucal removível e com o Bionator. 1997. 334 f. Tese (Livre-Docência)-Faculdade de Odontologia de Araraquara, Universidade Estadual Paulista, Araraquara, 1997.

26. MAYS, R. A. A cephalometric comparison of two types of extra oral appliance used with the edgewise mechanism. Am J Orthod, St. Louis, v. 55, p. 195-196, 1969

27. MELSEN, B. Effects of cervical anchorage during and after treatment: an implant study. Am J Orthod, St. Louis, v. 73, p. 526-540, 1978.

28. MELSEN, B.; ENEMARK, H. Effects of cervical anchorage during and after treatment: an implant study. Trans Eur Orthod Soc, [S. I.], v. 45, p. 435-447, 1969

29. MERRIFIELD, L. L.; CROSS, J. J. Directional forces. Am J Orthod, St. Louis, v. 57, p. 435-464, 1970.

30. MILLS, C. M.; HOLMAN, G.; GRABER, T. M. Heavy intermittent cervical traction in class II treatment: a longitudinal cephalometric assessment. Am J Orthod, St. Louis, v. 74, p. 361-379, 1978.

31. MITANI, H.; BRODIE, A. G. Three plane analysis of tooth movement, growth, and angular changes with cervical traction. Am J Orthod, St. Louis, v. 40, p. 80-94, 1970

32. NEWCOMB, M. R. Some observations on extra oral treatment. Angle Orthod, Appleton, v. 28, p. 131-148, 1958

33. NIELSEN, I. L. Maxillary superimposition: a comparison of three methods for cephalometric evaluation growth and treatment change. Am J Orthod Dentofacial Orthop, St. Louis, v. 95, p. 422-431, 1989

34. NIELSEN, I. L. Vertical malocclusion: etiology, development, diagnosis and some aspects of treatment. Angle Orthod, Appleton, v. 61, p. 247-260, 1991.

35. RINGERBERG, Q. M.; BUTTS, W. C. A controlled cephalometric evaluation of single-arch cervical traction therapy. Am J Orthod, St. Louis, v. 57, p.179-185, 1970.

36. RIOLO, M. et al. An atlas of craniofacial growth, cephalometric standards from the University School Growth Study. An Arbor: The University of Michigan, 1974

37. RODHES, J. D. Cephalometric indications of developing skeletal discrepancies in young children. 1990. Citation (Master of Science)-Baylor College of Dentistry, Dallas, 1990.

38. ROOT, T. L. JCO interviews on headgear. J Clin Orthod, Boulder, v. 9, p. 20-41, 1975

39. ROTHSTEIN, T. L. Facial morphology and growth from 10-14 years of age in children presenting class II, Div.1, malocclusion: a comparative roentgenographic cephalometric study. Am J Orthod, St. Louis, v. 60, p. 619-620, 1971.

40. SANDUSKY, W. C. Cephalometric evaluation of the effects of the Kloehn type of cervical traction used as an auxiliary with the Edgewise mechanism following Tweed's principles for correction of class II, division 1 malocclusion. Am J Orthod, St. Louis, v. 51, p. 262-287, 1965.

41. URSI, W. J. S. Alteração clínica da face em crescimento: uma comparação entre os aparelhos extrabucal cervical, Frankel, e Herbst, no tratamento da classe II. 1993. 168 f. Dissertação (Doutorado em Ortodontia)- Faculdade de Odontologia de Bauru, Universidade de São Paulo, Bauru, 1993.

42. WEINBERGER, T. W. Extra oral traction and functional appliances - a cephalometric comparison. Br J Orthod, London, v.1, p. 35-39, 1974.

43. WIESLANDER, L. Early or late cervical traction therapy of class II malocclusion in the mixed dentition. Am J Orthod, St. Louis, v. 67, p. $432-439,1975$.

\section{Endereço para correspondência}

Lídia Parsekian Martins

Rua Voluntários da Pátria, $n^{\circ} 1766$, Centro,

CEP 14801-320, Araraquara - SP, Brasil.

e-mail: joel_cm@terra.com.br 